\title{
A hygrothermal dynamic zone model for building energy simulation.
}

\author{
Victor Manuel Soto Frances ${ }^{\mathrm{a}, *}$, Emilio Jose Sarabia Escriva ${ }^{\mathrm{a}}$, Jose Manuel \\ Pinazo Ojer ${ }^{\mathrm{a}}$ \\ ${ }^{a}$ Departamento de Termodinamica Aplicada. ETSII. Universitat Politecnica de Valencia. \\ $C /$ Camino de vera $s / n$. 46022 Valencia (Spain)
}

\section{Abstract}

The IEA agency in its annex 41 deals with the modelling of heat, air and moisture (HAM) transfer in whole buildings. In its words, coupling among these phenomena is crucial for future energy optimization of buildings.

Computational Fluid Dynamics (CFD) is difficult and costly to use for everyday practice. Instead, popular building energy simulation software tools (BES) use simplified models popularly known as multi-zone models. Historically the thermal methods were developed separately from the multi-zone airflows and with different purposes. In well-known multi-zone flow softwaretools like CONTAM [1] or COMIS [2], the airflow is decoupled from the thermal problem. BES try to gather those separated efforts and couple both heat and the airflow phenomena using different strategies [3].

All this separated development and the increase in computation capacity, has led to a point where improvements are needed [3].

\footnotetext{
${ }^{*}$ Corresponding author

Email addresses: vsoto@ter.upv.es (Victor Manuel Soto Frances), emases@upvnet.upv.es ( Emilio Jose Sarabia Escriva), jmpinazo@ter.upv.es ( Jose Manuel Pinazo Ojer)
} 
After a critical review of recent hygrothermal zone models, we present a proposal of a simplified zone model for the air-water mixture dynamics which can be used in BES. The resulting dynamical state variables are the zone dry temperature, absolute humidity, total pressure and dry air mass content. This means that, in contrast with other literature models, we employ three intensive and one extensive variables respectively. Moreover, the reference height level inside the zone cannot be chosen arbitrarily. The dynamic is obtained by using zone energy balance, balances of dry air and water mass content and the Equation of State for the wet air mixture. The zone can store dry air and water, therefore their density can change with time inside the volume. Inside the zone an hydrostatic pressure field is assumed with no kinetic energy storage.

The resulting model is a made up of three non-linear ordinary differential equations and one algebraic equation. The model is automatically capable of dealing with wet air saturation conditions by using a special control signal $\alpha_{\text {control }}$.

Keywords: HAM, heat airflow moisture zone model, building energy simulation, multi-zone flow, saturation conditions

\section{Nomenclature}

\section{Acronyms}

j Mass diffusion flux $\left[\mathrm{kg} \cdot \mathrm{m}^{-2} \mathrm{~s}^{-1}\right]$

$\mathbf{n}$ Mass flux in $\left[\mathrm{kg} \cdot \mathrm{m}^{-2} \mathrm{~s}^{-1}\right]$

$\mathbf{v}$ Mass average velocity or barycentric velocity $\left[\mathrm{m} \cdot \mathrm{s}^{-1}\right]$ 
$\Delta H$ Enthalpy change for water, from liquid to vapor at $0\left[{ }^{\circ} \mathrm{C}\right], 2501\left[k J \cdot \mathrm{kg}^{-1}\right]$

$\Delta U$ Internal energy change for water in a phase change from liquid to vapour at $0\left[{ }^{\circ} \mathrm{C}\right], 2375\left[\mathrm{~kJ} \cdot \mathrm{kg}^{-1}\right]$

$\dot{m}$ Mass flow rate $\left[\mathrm{kg} \cdot \mathrm{s}^{-1}\right]$

$\phi$ Relative humidity.

$c_{p, d a}$ Specific heat at constant pressure of dry air $1\left[k J \cdot k g^{-1}\right]$

$c_{p, v}$ Specific heat at constant pressure of water vapor $1.805\left[k J \cdot k g^{-1}\right]$

$c_{v, d a}$ Specific heat at constant volume of dry air $\left(c_{p, d a}-R / 1000 / M_{d a}\right)[k J$. $\left.k g^{-1}\right]$

$c_{v, v}$ Specific heat at constant volume of water vapour $\left(c_{p, v}-R / 1000 / M_{v}\right)$ $\left[k J \cdot k g^{-1}\right]$

$H_{M}$ Scale height $H_{M}=\frac{R_{M} \cdot T_{d b}}{g}[m]$

$R_{M}$ Gas ideal constant divided by the molecular mass $M$.

c Relative z-coordinate for a zone $[m]$.

g Gravity acceleration $9.81\left[m \cdot s^{-2}\right]$

$\mathrm{H}$ Total enthalpy of the wet air $[k J]$

h Wet air enthalpy $\left[k J \cdot k g_{d a}^{-1}\right]$

M Molecular mass (dry air 28.965) (water 18.015) $\left[\mathrm{kg}^{\mathrm{k}} \mathrm{kmol}^{-1}\right]$

n Number of moles. 
R Gas ideal constant $8314.3\left[\mathrm{~J} \cdot \mathrm{kmol}^{-1} \cdot \mathrm{K}^{-1}\right]$

U Internal energy $[\mathrm{kJ}]$.

W Specific humidity $\left[k g_{v} \cdot k g_{d a}^{-1}\right]$

\section{Greek Symbols}

$\omega$ Mass fraction

\section{Superscripts}

e Inlet flow

s Outlet flow

\section{Subscripts}

b Bottom height of the zone.

da Dry air.

db Dry bulb.

diff Diffusive

M Dry air or water.

sat Water vapor saturation state.

t Total

u Upper height of the zone.

w Liquid water 


\section{Introduction}

With the increase in computational capabilities the scientific literature in recent years has been focusing in what is called; heat, air and moisture modelling of whole buildings (HAM acronym is usually used). This implies taking into account the adsorption and diffusion of water in solids and practical heat and moisture transfer in solids, which has not been brought to practice until recently [4]. The IEA annex 41 (see [5]) is devoted to this task. IEA says that coupling among the phenomena is crucial for future energy optimization of buildings. Even recently a study performed by Lorenzetti et al. [3] points out the need for better design tools to enable the construction of net zero energy buildings. An accurate determination of the heat load (both sensible and latent), requires a detailed calculation of the coupled heat and moisture transfer, along with the airflow inside buildings and the interactions with HVAC installations and the environment conditions. However, at the same time, the models should be simple enough so that a professional might use them daily at a low cost. Originally the models for airflow networks aimed at determining the dispersion of contaminants inside buildings and had no special interest in the thermal problem. The outputs from the latter were just inputs to the airflow problem. There are very recent efforts that try to couple both (see for instance [6] or [7]). As Lorenzetti suggests [3], in this paper we propose a simplified fully coupled hygrothermal zone model for building energy simulation. 


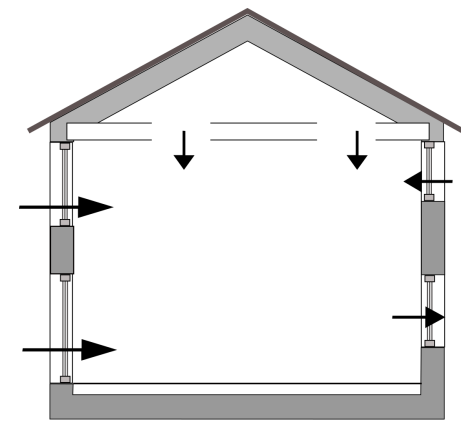

A

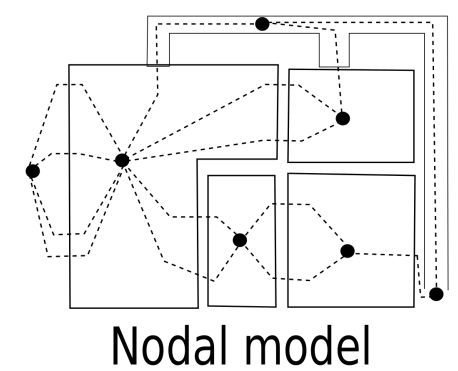

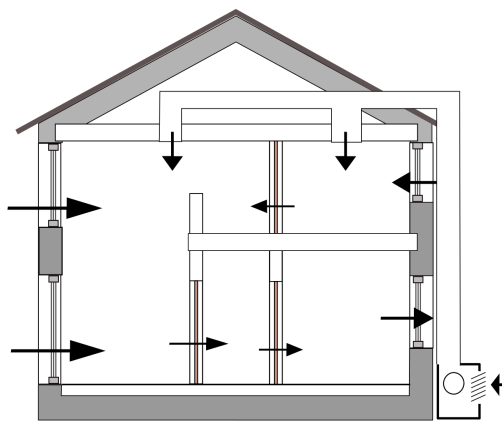

$\mathrm{B}$

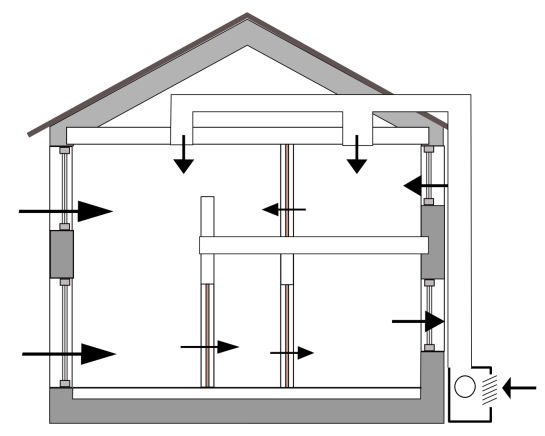

B

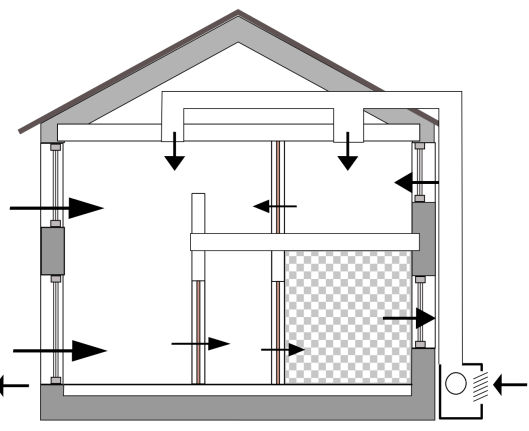

C

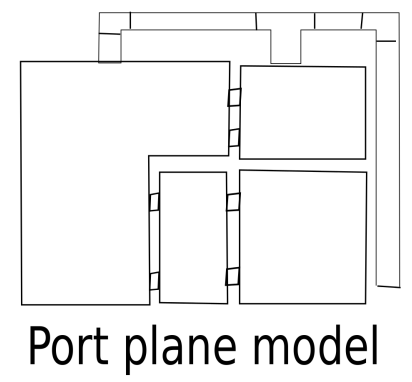

Figure 1: Top: (A) Single-zone model (coarse-grained) (B)Multi-zone+duct network (Intermediate-grained) (C) Multi-zone+Duct network+Embedded detail model (chessboard zone) (mixture of very fine and intermediate grained). Bottom: nodal versus port plane representations of $\mathrm{B}$ model.

\section{State of the art}

This section is intended for briefly reviewing and discussing the current methods and models, in order to compare our proposal.

The spatial resolution of the problem is a main issue to take care of. The models are classified by IEA annex 41 as: very fine-grained, fine-grained, intermediate-grained and coarse-grained. Axley [8] made a critical review of multi-zone airflow modelling in buildings. He classifies the multi-zone 
models similarly to the IEA. Figure (1) serves to clarify these accepted types of models.

In a very recent building simulation review paper by Wang et al. [9] which covers a period between 1987-2014, they classify the techniques employed in indoor ventilation simulation. The coupling of different thermal and airflow models prevails over fully coupled hygrothermal airflow models (see for instance [10], [11], [12]).

Santamouris et al. in chapter two of their book [13] explain in detail, the analytical methods and computing tools for ventilation. In conventional multi-zone airflow analysis, building systems are idealized as collections of zones and duct junctions linked by discrete (flow-limiting, or flow resistances) airflow paths (represented by dashed lines in figure(1)). Envelope wind-pressure and temperatures within the zones and ducts are specified as boundary conditions and inputs (see [14]). The latter come from energy simulation programs (BES), thus creating a coupling interface which is solved in different ways [12]. Temperature and species (contaminants) are assumed not to vary spatially within a zone and do not modify the air density. This is known as well-mixed zone hypothesis and has a drawback that the information about the dispersion of the contaminants within the zone is lost. Each zone volume is reduced to a point or node placed at a reference level and the unknown, assigned to it, is the total pressure. In our case this level cannot be chosen arbitrarily. Then, equations governing the behaviour of the system as a whole are formed by demanding zone mass airflow rates to be conserved (without mass storage or mass is taken as quasi-steady). Finally, these equations are complemented by assuming that an hydrostatic pressure 
field exist in each zone in order to achieve closure of the problem (see the manual of CONTAM [1]). As [13] points out, this hypothesis violates the conservation of mechanical energy. However the problem appears because only the mechanical energy (kinetic and geo-potential) is included in the balance, since, as mentioned, traditionally the airflow methods are decoupled from the thermal problems.

As it will be shown, this hydrostatic pressure field hypothesis leads to no energy balance violation if the internal energy is included. The hydrostatic field has the drawback (see [3]) that, since there is no momentum in the zone, the wind-driven flows are not handled properly and therefore constrains the capabilities of the model. Obviously, including the air internal energy means that the airflow and thermal problems are directly coupled and should be solved simultaneously. As Lorenzetti et al. [3] point out, the direct coupling is a desirable feature, but unfortunately the system becomes stiff (that is one reason why there are few fully coupled modelling attempts [9]) and emphasize, logically, the need for new solution methods. Emmerich et al. in 2011 [15] proposed a modification of the traditional method which includes the thermal problem and tries to solve the stiffness issue. Unfortunately their energy balance equation only takes into account the internal energy and they do not include the water component. The actual difficulty is that buildings have several subsystems (solid parts, air, HVAC systems, etcetera) with different response times which naturally make the problem stiff. So the stiffness issue in building energy simulation although involves the thermalairflow coupling is, in fact, far more complex. We work in an innovative way to solve such problems based on Discrete Event Simulation (DEVS) 
methods. The full explanation of the method (see for instance [16]) falls out of the present scope. A first step towards a reformulation of the building energy simulation using this DEVS formalism and QSS methods, has already been done by us in [17], using the successive state transition method (not collected in [9]). The present paper originates from the need of going a step further by deducing the dynamics of the water air mixture for a multi-zone model to be employed in a fully coupled whole-building DEVS model.

\subsection{Discussion and motivations}

In all the traditional literature about multi-zone airflow there is a reference to the air as a mixture of gases which fulfil the Dalton's law, that is, the total pressure is the sum of the partial pressures (see user manual of CONTAM [1]). Typically, dry air is a mixture (in mass fraction) of the following gases; $N_{2}(0.7554), O_{2}(0.2314), A r(0.0127), C O_{2}(0.0005)$, while water is just considered another component or contaminant (see [1] or CHAMPS [18]). Literature refers to the mixture simply as air. In general, multi-component heat and mass transfer is not an easy matter (see [19]) due to cross effects. Therefore in psychrometry it is assumed that dry air behaves as a single component and water as another one, thus resulting in a binary mixture known as wet-air. This represents another constrain for the model. However water has the particularity, compared with all other contaminants, that can change its phase, that is, it may condense and this has, obviously, noticeable effects on the energy balance. In [13] the name multi-zone multi-physics analysis is given to the case where a mixture of one or several contaminants is considered.

Gibbs phase rule says that for a binary mixture and one phase the degrees 
of freedom are three. However in case condensation occurs, there are two phases and then the degrees of freedom are only two. This change in the number of state variables from three to two would change the number of equations which represent the dynamics. However, in our formulation we have kept the original system of equations, three equations (one for each state variable), and we have introduced the control parameter $\alpha_{\text {control }}$ into the independent variables, which forces, if necessary, the saturation conditions of the mixture.

Unfortunately, looking through the recent research about wet air dynamic models employed in multi-zone models, did not result, from our point of view, in a good enough model for yearly simulations (see (2003)[26],(2008)[20], (2010)[23], (2011)[21], [25], (2012)[18], (2015)[22]) . Qin et al. [20] ,[21] presented a hygrothermal airflow model (for wet air) following CONTAM's methodology. CONTAM uses the total density of the air and the concentration (mass fraction) of each contaminant while the zone temperature is used as an input. Qin considered as dynamical state variables, only two; the dry temperature and the water vapour content in $v\left[\mathrm{kgm}^{-3}\right]$, since they assumed quasi-steady conditions, or in other words, that the rate of change of the air mass within the zone is zero. The dynamics of the zone results from just two balances; energy and water. In the energy case only the internal energy is taken into account while the air mass is assumed to be fixed. Qin takes into account the saturation of the wet air by limiting the vapour content to the saturation value $v_{\text {sat }}(T)\left[\mathrm{kgm}^{-3}\right]$. The excess of water is removed as a sink and the heat released added as an internal gain, but this has to be done explicitly and is inconsistent with the assumption that the mass of air 
is practically constant.

Something similar happens in a more recent paper from Berger et al. [22]. Berger's paper is mainly focused on solving a wet air zone model by using an interesting new method named Proper Generalised Decomposition. The model, which Berger tries to solve, is explained in the appendix of [22]. Unfortunately the model is also flawed for our purposes. They make also two balances, water and energy, resulting in a system with two dynamical variables; the dry temperature and the vapour pressure, while, as explained before, three variables are needed to determine the state of a binary mixture. In their deduction they are implicitly assuming that the dry air density (and therefore, the zone dry air mass) and the total pressure are constant. This creates inconsistencies. On one hand the vapour pressure is a dynamical variable, but since the total pressure is the sum of the vapour and the dry air pressure, the latter must change so as to keep the total pressure constant, while on the other hand, as the temperature is also an independent dynamical variable, it has an effect on the dry air pressure whose change, in turn, may not match that needed by the total pressure constrain. Moreover the model does not deal with the possibility of reaching the water saturation conditions of the wet air and airflows are not modelled but must be given parameters to the problem.

Other proposals like [23], [24] [25] or [26] present improvements, but for similar reasons, still do not fit our goals.

Figure (1) shows a more modern view of the multi-zone airflow which Axley [8] calls port-plane and Santamouris et al. [13] multi-port control volumes. Our approach is closer to this last idea. A more detailed picture 


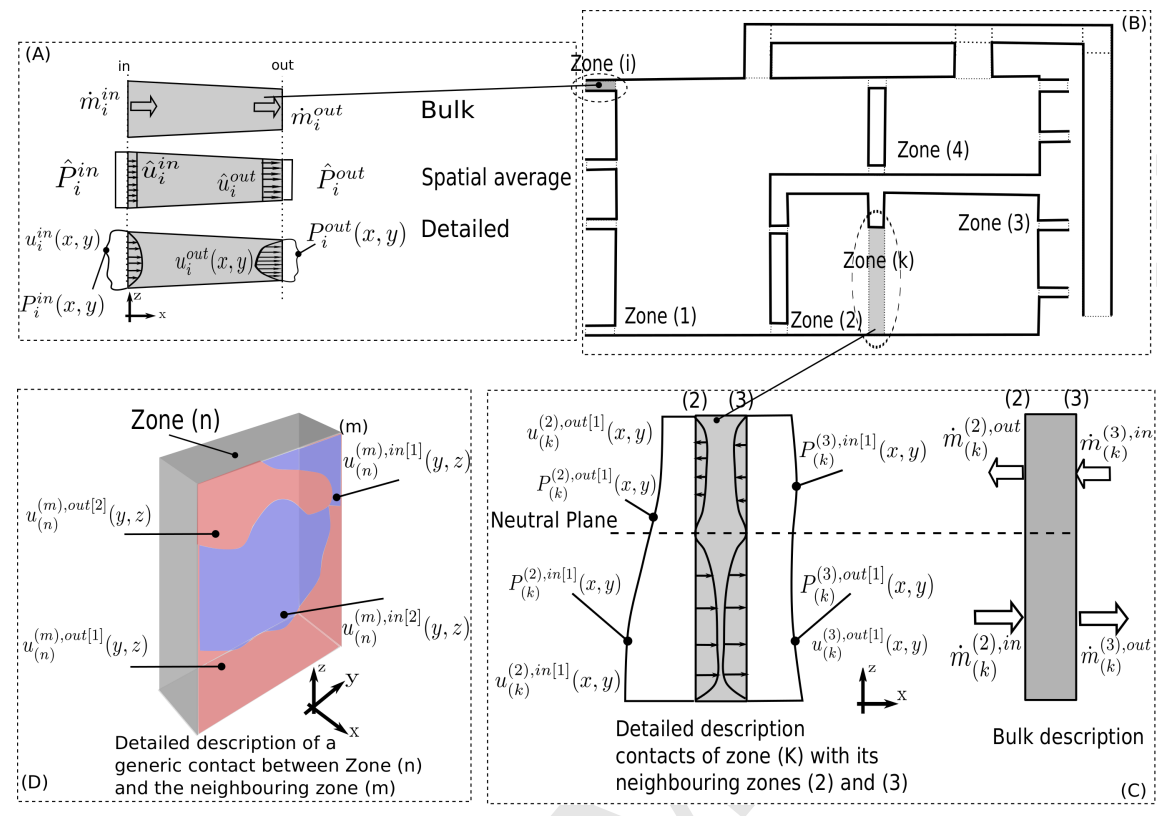

Figure 2: Multi-port zone model of a multi-zone building model. Detail of the description of the flow at the ports. (A) Two-port zone and one sense per port, (B) Multi-zone model, (C) Two-port zone with one outlet and inlet per port, (C) A generic port description, blue and red color indicate zone $(n)$ ingoing or outgoing fluxes respectively.

of figure (1) is shown in figure (2). The building is divided into control volumes and at their boundaries there are ports where a exchange of mass is possible. All elements are considered as control volumes but are classified and characterised according to some criteria. The flow variables at each port may be expressed by a detailed, spatially averaged or a bulk model.

By $\dot{m}_{(i), d a}^{(j), o u t}$ and $\dot{m}_{(i), d a}^{(j), i n}$ we denote the bulk dry air mass flow rate going out/in (respectively) from/to zone $(i)$ to/from zone $(j)$. Whenever the zone ( $i$ ) under study is implicitly understood, the sub-index is dropped and it is written just $\dot{m}_{d a}^{(j), \text { out }}$. If there were several in or out ports between zone $(i)$ and $(j)$ they are identified by a k-index as for instance $\dot{m}_{(i), d a}^{(j), \text { out }[k]}$. For simplicity 
we assume just one outlet and inlet port from a neighbouring zone $(j)$ to the current one and therefore no indexing of the ports is necessary. Our proposed model would be placed between very fine-grained and intermediate-grained models of the IEA classification.

There are two big standard approximations to get a coupled model [27]: internal and external coupling. Internal coupling means that the equations describing the HAM transport in the building envelope, the room model and the airflow are solved in the same domain. External coupling means that models are solved in different domains, while information between the domains is exchanged at different times. This last one is the more common approximation as aforementioned (see [9]) but has drawbacks. The model presented here is intended to be used in the internal coupling mode and the solution method will be based on an event driven simulation (DEVS).

Summarizing, our hygrothermal zone model is represented by three intensive degrees of freedom; the uniform dry bulb temperature, the reference total pressure and the specific humidity. Both the shape and volume of the zone need to be taken into account, because, contrary to traditional methods, the zone reference height cannot be chosen arbitrarily but depends on the zone geometry. The model deals naturally with the saturation conditions. The coupling terms among neighbouring zones may include the heat and moisture flow through the solid boundaries $([29]),([23])$ and the convective or diffusive moisture flows through openings. The flow sub-models or two-port zone models, from AIRNET for instance or others [30], might be employed in these coupling terms.

Finally, it is worthwhile to remember and to stress that these types of 
models are a rough simplification (see [20]).

\section{Zone model proposal}

The model is built from the very basic principles in order to be as selfcontained as possible.

\subsection{Ideal gas model in a gravitational field.}

Independently of the spatial level of detail, the state equation for the fluid must hold at every spatial point or region. We assume that the air is a mixture of gases which fulfil de Dalton's law. For each gas in the mixture the ideal gas law is assumed to be valid:

$$
P V=n R T_{d b}
$$

By using the molecular mass $M$ of the species, equation (1) can be rewritten as:

$$
\begin{aligned}
P V & =n \cdot M \cdot \frac{R}{M} \cdot T_{d b}=n \cdot M \cdot R_{M} \cdot T_{d b}=m \cdot R_{M} \cdot T_{d b} \\
\rho= & \frac{m}{V}=\frac{P}{R_{M} T_{d b}}
\end{aligned}
$$

A typical hypothesis in the multi-zone airflow literature is that the enclosed gas is quiet and under the effect of just the gravitational field. Thus the pressure spatial distribution corresponds to the hydrostatic profile which for a typical room is quite uniform.

The profile is the result of a balance of forces (see figure (3)).

$$
P d A-g \rho d A d z-(P+d P) d A=0
$$




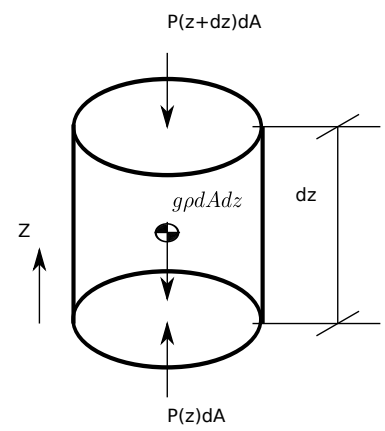

Figure 3: Balance of forces of a control volume of matter in a gravitational field.

$$
\frac{d P}{d z}+g \rho=0
$$

Clearing the density $\rho$ from equation (2) into equation (4), we get:

$$
\frac{d P}{d z}=-g \frac{P}{R_{M} \cdot T_{d b}}=-\frac{P}{H_{M}\left(T_{d b}\right)}
$$

In the most general case where the temperature is a function of the height $T_{d b}=T_{d b}(z)$ the integration of equation (5) from a reference height $z_{\text {ref }}$ gives:

$$
P(z)=P_{r e f} \cdot e^{-\int_{z_{r e f}}^{z} \frac{d z^{\prime}}{H_{M}\left(z^{\prime}\right)}}
$$

The term $H_{M}=\frac{R_{M} \cdot T_{d b}}{g}$ is known, in atmospheric science, as the scale height, defined as the increase in altitude for which the atmospheric pressure decreases by a factor of $e^{-1}$. The temperature stratification is neglected and a spatial averaged temperature is used instead. Thus by assuming that $T_{d b} \neq f(z), H_{M}$ depends only on the temperature, not the height, and equation (6) transforms into:

$$
P=P_{r e f} \cdot e^{-\frac{\left(z-z_{r e f}\right)}{H_{M}\left(T_{d b}\right)}}
$$

For instance, in atmospheric science a mean value of $260[K]$ in equation $(7)$ gives quite accurately the profile of the air density up to around a height of $7[k m]$. 
By using the notation $H_{M}\left(T_{d b}\right)$, we point out that the scale height depends on the species (molecular mass $M$ ) and on the temperature (which is considered spatially uniform). Due to its exponential character, equation (7) is linearised with respect to the $z$ coordinate at a certain reference height $z_{\text {ref }}$, for buildings applications, as:

$$
\begin{aligned}
& P(z) \approx P_{r e f}+\left.\frac{d P}{d z}\right|_{z=z_{r e f}} \cdot\left(z-z_{r e f}\right) \\
& P(z) \approx P_{r e f}\left(1-\frac{\left(z-z_{r e f}\right)}{H_{M}\left(T_{d b}\right)}\right)=P_{r e f}-g \cdot \rho_{r e f}\left(z-z_{r e f}\right)
\end{aligned}
$$

Equation (8b) is the well known hydrostatic pressure equation. Using this expression into $(2 \mathrm{~b})$, the linearised density variation with height is:

$$
\rho(z)=\rho_{\text {ref }}\left(1-\frac{\left(z-z_{r e f}\right)}{H_{M}\left(T_{d b}\right)}\right)
$$

From equation (9) the greater $T_{d b}$ the more uniform the density. Below $z_{r e f}$ the density is higher than $\rho_{\text {ref }}$ and vice versa. Summarizing our assumptions are:

- Hydrostatic pressure (remark: the density is not spatially uniform).

- The fluid is quiet within the zone.

- The temperature is spatially uniform or represents a zone mean value.

Compared to other models like CONTAM (see an example in [15]), our proposal needs to compute the zone reference level.

The reference height inside the zone cannot be chosen arbitrarily, since we want to keep track of the mass content of the zone. In what follows, the data $P, \rho, T$ which is referred to that special height, will have the ref 
sub-index. That height in relative coordinates (i.e., taking the origin at the bottom of the zone) is named $\left(c_{r e f}\right)$. In order to calculate that special zone coordinate we proceed as follows.

The zone air mass is given by the integral (10a), taken from the bottom $c=0$ to the top $c=c_{u}$ of the zone. The density is not uniform but given by (9) and $A\left(c^{\prime}\right)$ is the zone cross sectional area at height $c^{\prime}$. The zone reference level is chosen so that equation (10b) is satified:

$$
\begin{aligned}
& m=\int_{c=0}^{c=c_{u}} \rho\left(c^{\prime}\right) d V\left(c^{\prime}\right)=\int_{c=0}^{c=c_{u}} \rho_{r e f}\left(1-\frac{\left(c^{\prime}-c_{r e f}\right)}{H_{M}\left(T_{d b}\right)}\right) A\left(c^{\prime}\right) \cdot d c^{\prime} \\
& m=\rho_{\text {ref }} \cdot V=\rho_{\text {ref }} \cdot \int_{c=0}^{c=c_{u}}\left(1-\frac{\left(c^{\prime}-c_{r e f}\right)}{H_{M}\left(T_{d b}\right)}\right) A\left(c^{\prime}\right) \cdot d c^{\prime}
\end{aligned}
$$

Therefore the $c_{r e f}$, in general, is obtained by clearing its value from the following equation:

$$
V=\int_{c=0}^{c_{u}} A\left(c^{\prime}\right) \cdot d c^{\prime}=\int_{c=0}^{c_{u}}\left(1-\frac{c^{\prime}}{H_{M}(T)}+\frac{c_{r e f}}{H_{M}(T)}\right) A\left(c^{\prime}\right) \cdot d c^{\prime}
$$

or rearranging the terms and multiplying by $H_{M}(T)$ :

$$
\int_{c=0}^{c_{u}}\left(c^{\prime}-c_{r e f}\right) A\left(c^{\prime}\right) \cdot d c^{\prime}=0
$$

and finally:

$$
c_{r e f}=\frac{\int_{c=0}^{c_{u}} c^{\prime} \cdot A\left(c^{\prime}\right) \cdot d c^{\prime}}{V}
$$

Observe that $c_{\text {ref }}$ does not depend on the type of species inside the zone or the temperature, but just on geometric properties. It represents the zone geometrical height center, not the zone center of mass. The height of the zone center of mass will be below $c_{r e f}$ and only in the limit case when $\rho$ is uniform, both are equal. 


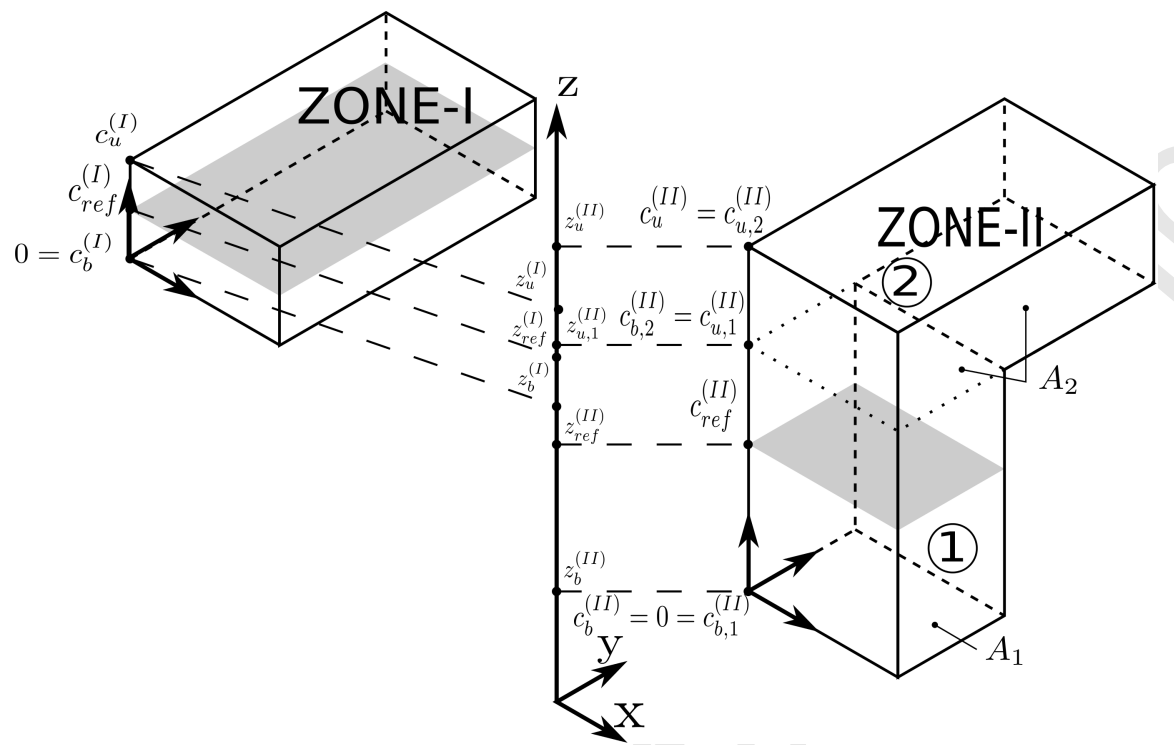

Figure 4: Example zones. Nomenclature for the zone bottom (b), upper $(\mathrm{u})$ heights in relative (c) or absolute (z) coordinates.

For instance let us take a parallelepipedical case, i.e. a case where $A \neq$ $f(c)$ (see zone-I in figure (4)), the zone gas mass content, i.e. equation (10b), is written as:

$$
m=\rho_{\text {ref }} \cdot A \cdot\left(c_{u}-\frac{c_{u}^{2}}{2 H_{M}\left(T_{d b}\right)}+\frac{c_{r e f}}{H_{M}\left(T_{d b}\right)} \cdot c_{u}\right)
$$

By choosing $c_{r e f}=c_{u} / 2$ (half the height of the zone), or in other words, computing $c_{r e f}$ from equation (13), the mass content of the zone is just:

$$
m=A \cdot c_{u} \cdot \rho_{\text {ref }}=V \cdot \rho_{\text {ref }}
$$

We would like to stress that $\rho_{\text {ref }}$ is used to know the total zone gas mass content $m$. Remark: that height does not depend on the amount of mass, the species or its spatial distribution. 
Let us consider another zone, not so simple, to illustrate the idea. In figure(4) another zone named zone-II, is made up of two parallelepiped zones. The calculation of $c_{r e f}$ using equation (13) gives:

$$
c_{r e f}=\frac{1}{2} \cdot \frac{A_{2}\left(c_{u, 2}^{2}-c_{u, 1}^{2}\right)+A_{1} \cdot c_{u, 1}^{2}}{A_{2} \cdot\left(c_{u, 2}-c_{u, 1}\right)+A_{1} \cdot c_{u, 1}}
$$

As mentioned at the beginning of this section, the equation of state $(2 \mathrm{~b})$ must hold for any gas species at any place. Nevertheless, at the specially chosen reference level $c=c_{r e f}$, the following equation is valid:

$$
P_{\text {ref }}=\frac{m}{V} \cdot R_{M} \cdot T_{d b}
$$

, therefore two signals, $P_{r e f}$ and $T_{d b}$, are enough to track the zone mass content, while equations (8b) and (9) give the spatial height distribution of $P$ and $\rho$ inside the zone.

Finally, figure (5) shows an example scheme to clarify our proposal for the zone dynamical variables.

\subsection{Wet air.}

In this section the well-known properties of wet air from psychrometry are collected and rewritten according to our nomenclature in order to be used by our model. The air is considered to be a binary mixture of: a non-condensing mixture of gases named dry air (da) and water vapour (v). In the mixture both components behave as if each one was in its own, inside the volume. Therefore the spatial distribution of the total pressure is given by adding the 


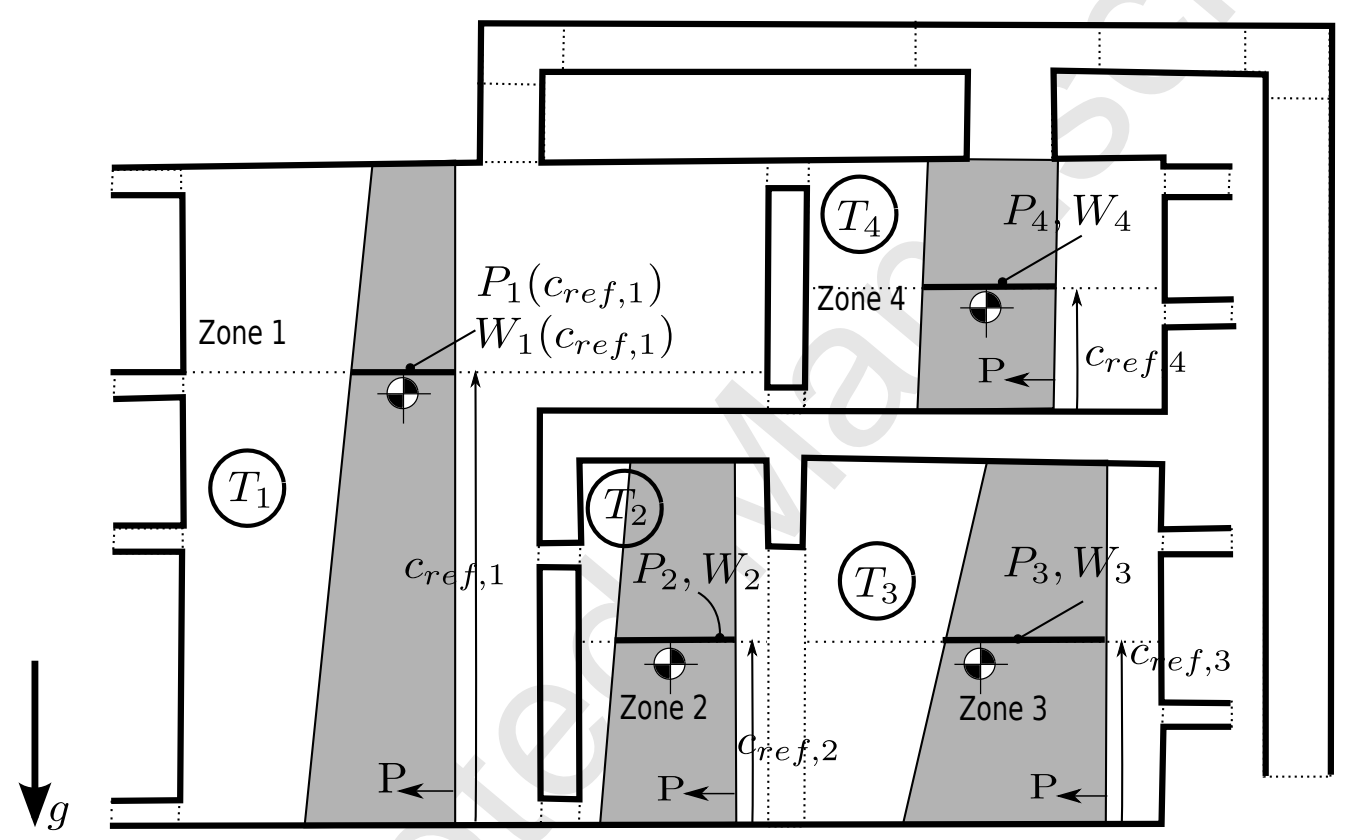

Figure 5: Example scheme of the zone model proposal. Temperatures $T_{d b}$ are uniform inside the zone, while pressure and maybe the absolute humidity depend on zone height. The reference zone level $c_{r e f}$ cannot be chosen arbitrarily but is a height geometric center. The center of mass is always below the reference level, the colder the zone, the greater the distance of the center of mass form the reference level, although for typical zones we have assumed that the center of mass is fixed. 
partial pressures:

$P(z)=P_{d a}(z)+P_{v}(z)=P_{r e f, d a}-g \cdot \rho_{r e f, d a}\left(z-z_{\text {ref }}\right)+P_{r e f, v}-g \cdot \rho_{\text {ref }, v}\left(z-z_{\text {ref }}\right)$

$P(z)=\left(P_{r e f, d a}+P_{r e f, v}\right)-g \cdot\left(\rho_{r e f, d a}+\rho_{r e f, v}\right)\left(z-z_{r e f}\right)=$

$P(z)=P_{\text {ref }}-g \cdot \rho_{\text {ref,da }}\left(1+W_{\text {ref }}\right)\left(z-z_{\text {ref }}\right)$

The dry air and the water vapour satisfy its respective Equation of State (2b) at each spatial point of the zone. However if it is written adding all the species, then a similar state equation is only valid at $c_{r e f}$, due to the presence of the gravity field. At that height the mass of all the species is taken into account. Therefore:

$$
\begin{gathered}
P_{r e f, d a} V=n R T_{d b}=\frac{m_{d a}}{M_{d a}} R T_{d b} \\
P_{r e f, v} V=n R T_{d b}=\frac{m_{v}}{M_{v}} R T_{d b}
\end{gathered}
$$

Adding the pressures gives:

$$
P_{r e f} \cdot V=\left(P_{r e f, d a}+P_{r e f, v}\right) V=\frac{m_{d a}}{M_{v}}\left(\frac{M_{v}}{M_{d a}}+W_{r e f}\right) \cdot R \cdot T_{d b}
$$

If we name ${ }^{1} C T E_{P t}=P_{r e f} \cdot V / R$ then the mass of dry air contained in the volume $\mathrm{V}$ of the zone is:

$$
m_{d a}=\frac{C T E_{P t} \cdot M_{v}}{T_{d b}\left(\frac{M_{v}}{M_{a s}}+W_{r e f}\right)}
$$

The density distribution of the wet air is given by:

$$
\rho(z)=\rho_{d a}(z)+\rho_{v}(z)=\rho_{d a}(z)(1+W(z))
$$

\footnotetext{
${ }^{1}$ This definition contains the size $V$ of the zone and is preferable for applying the QSS method in DEVS for reason that would be lengthy to explain here.
} 
Note: The specific humidity $W$ would also be a function of the height $z$ inside the zone. However its variation in practice is quite small, in the order of $0.1 \%$ or less, and therefore, as a relative value, might be considered as spatially constant within the zone.

Taking as reference states for internal energy calculation; $0\left[{ }^{\circ} \mathrm{C}\right]$ for dry air and $0\left[{ }^{\circ} \mathrm{C}\right]$ liquid for water, the internal energy of a mass $m_{d a}$ of dry air and $m_{v}$ of water vapour at a temperature $T_{d b}$, has the following expression:

$$
\begin{aligned}
U= & U_{d a}+U_{v}=m_{d a} \cdot c_{v, d a} \cdot T_{d b}+m_{v} \cdot\left(\Delta U+C_{v, v} \cdot T_{d b}\right)= \\
& =m_{d a} \cdot\left[c_{v, d a} \cdot T_{d b}+W_{r e f} \cdot\left(\Delta U+c_{v, v} \cdot T_{d b}\right)\right]= \\
& =m_{d a} \cdot u
\end{aligned}
$$

The enthalpy of the mixture is given by:

$$
\begin{aligned}
H= & H_{d a}+H_{v}=m_{d a} \cdot c_{p, d a} \cdot T_{d b}+m_{v} \cdot\left(\Delta H+C_{p, v} \cdot T_{d b}\right)= \\
& =m_{d a} \cdot\left[c_{p, d a} \cdot T_{d b}+W_{r e f} \cdot\left(\Delta H+c_{p, v} \cdot T_{d b}\right)\right]= \\
& =m_{d a} \cdot h
\end{aligned}
$$

(Notice that $m_{d a} \cdot W_{r e f}=m_{v}$ ). In the literature frequently the enthalpy of wet air is given per kilo of dry air and a low capital letter is used $h$.

There are many correlations for the saturation pressure of water vapour, here equation (26) has been employed:

$$
P_{v, \text { sat }}=10^{7.5 \cdot\left(T_{\text {sat }}-273.159\right) /\left(T_{\text {sat }}-35.85\right)+2.7858} \quad,[P a]
$$

where $T_{\text {sat }}$ should be given in $[K]$. The specific humidity has the well-known relationship with the water vapour pressure:

$$
W\left(P_{t}, P_{v}\right)=\frac{M_{v}}{M_{d a}} \cdot \frac{P_{v}}{P_{t}-P_{v}}
$$




\subsection{Dynamical coordinates of the hygrothermal state of the zone.}

The variables which are going to be used to track the zone state are four (three intensive and one extensive):

- $x_{1}=W_{r e f}=W\left(z_{r e f}\right)=m_{v} / m_{d a}$ : Specific humidity at the reference height of the zone.

- $x_{2}=T_{d b}$ : dry bulb temperature of the mixture (which is spatially uniform along the zone).

- $x_{3} \cdot \frac{R}{V}=P_{\text {ref }}:$ Total pressure at the reference height of the zone $\left(C T E_{P t}=P_{\text {ref }} \cdot V / R=x_{3}\right)$.

- $m_{d a}$ : dry air mass of the zone.

In order to clear for these variables four equations are needed. One of them is algebraic. It corresponds to the $m_{d a}$ relationship with $\left\{x_{1}, x_{2}, x_{3}\right\}$, i.e., state equation (22). The other three will be ordinary differential equations. They come from the following balances inside the zone:

- energy.

- mass of water.

- mass of dry air.

\subsection{Fluxes}

Before going into the balances we need to define some preliminary concepts (see some standard book for details [31]). If $\mathbf{u}_{i}$ denotes the velocity of 
component $i$ with respect to a stationary coordinate reference frame, then the mass flux is defined by:

$$
\mathbf{n}_{i}=\rho_{i} \mathbf{u}_{i}
$$

If we sum the component mass fluxes, we obtain the total mass flux:

$$
\mathbf{n}_{t}=\sum_{i=1} \mathbf{n}_{i}=\rho \cdot \mathbf{v}
$$

The mass diffusion flux with respect to the mass average velocity is:

$$
\mathbf{j}_{i}=\rho_{i} \cdot\left(\mathbf{u}_{i}-\mathbf{v}\right)
$$

The mass flux of a component is related to the diffusion flux as:

$$
\mathbf{n}_{i}=\mathbf{j}_{i}+\rho_{i} \cdot \mathbf{v}=\mathbf{j}_{i}+\omega_{i} \cdot \mathbf{n}_{t}
$$

In general $\sum_{i} \mathbf{j}_{i}=0$, and for the case of the wet air binary mixture $\mathbf{j}_{d a}=-\mathbf{j}_{v}$. Psychrometry science prefers to use the absolute humidity $W$ than mass fractions $\omega$, thus the relationships among all of them are:

$$
\begin{aligned}
\omega_{v} & =\frac{W}{1+W} \\
\omega_{d a} & =\frac{1}{1+W}
\end{aligned}
$$

Therefore if instead of the fluxes we write the mass flow through a surface $\mathrm{S}$ of area $A_{S}$, then the following two relationships hold for the mass flow of dry air and water vapour as a function of $\dot{m}_{d i f f, v}=\mathbf{j}_{v} \cdot A_{S}$ and $\dot{m}_{t}=\mathbf{n}_{t} \cdot A_{S}$ :

$$
\begin{gathered}
\dot{m}_{d a}=-\dot{m}_{d i f f, v}+\frac{1}{1+W} \cdot \dot{m}_{t} \\
\dot{m}_{v}=\dot{m}_{d i f f, v}+\frac{W}{1+W} \cdot \dot{m}_{t}
\end{gathered}
$$


If $\dot{m}_{d a}$ and $\dot{m}_{d i f f, v}$ are preferred variables, by clearing $\dot{m}_{t}$ from (33) and substituting into (34), we obtain:

$$
\dot{m}_{v}=(1+W) \cdot \dot{m}_{d i f f, v}+W \cdot \dot{m}_{d a}
$$

In general the output from the flow-element models (see CONTAM [1]) used to compute the inter-zone mass flow is $\dot{m}_{t}$ and the diffusion of water vapour $\dot{m}_{d i f f, v}$. In order to simplify the exposition, the following mass and energy balances only take into account fluxes from openings, not from solid surfaces due to water adsorption or infiltration due to porous surfaces.

\subsection{Energy balance.}

The total energy content in the control volume or zone contains three terms:

$$
E_{\text {total }}=E_{\text {pot }}+U+E_{k i n}
$$

The geo-potential energy $E_{\text {pot }}$, the internal energy $U$, and the kinetic energy $E_{k i n}$ of the zone gases. Since we are neglecting the movement of the wet air inside the volume, the kinetic energy inside the volume is assumed to be negligible. This could be also extended by parametrizing the movement of the air inside the zone. However, the kinetic energy of the flows going into and out of the volume are not necessarily negligible. Therefore, in fact, what the model is assuming is that all the unbalanced kinetic energy is going to be transformed inside the volume into internal and potential energy. Nevertheless, we have neglected, as well, the kinetic energy of the incoming or outgoing flows.

The zone wet air energy balance taking into account for the airflow exchange with its neighbouring $(\mathrm{j})$-zones and solid boundary surfaces, is written 
as:

$$
\begin{aligned}
\frac{d E_{\text {total }}}{d t}=\frac{d E_{\text {pot }}}{d t}+\frac{d U}{d t}= & \dot{Q}_{\text {conv }}\left(T_{d b}\right)+\dot{Q}_{\text {sys }}+\sum_{j=1}\left(\dot{m}_{d a}^{(j), \text { in }} \cdot h_{d a}^{(j), \text { in }}+\dot{m}_{v}^{(j), \text { in }} \cdot h_{v}^{(j), \text { in }}\right)_{\text {inlets }}+ \\
& \dot{m}_{w}^{\text {src }} \cdot h_{w}-\sum_{j=1}\left(\dot{m}_{d a}^{(j), \text { out }} \cdot h_{d a}+\dot{m}_{v}^{(j), \text { out }} \cdot h_{v}\right)_{\text {outlets }}+ \\
& \sum_{j=1}\left(\dot{m}_{t}^{(j), \text { in }} g \cdot z^{(j), \text { in }}\right)_{\text {inlets }}-\sum_{j=1}\left(\dot{m}_{t}^{(j), \text { out }} g \cdot z^{(j), \text { out }}\right)_{\text {outlets }}
\end{aligned}
$$

or by using the psychrometric definition of wet air specific enthalpy $h\left[\mathrm{~J} \cdot k \mathrm{~g}_{d a}^{-1}\right]$, it can be rewritten as:

$$
\begin{aligned}
\frac{d E_{\text {total }}}{d t}= & \dot{Q}_{\text {conv }}\left(T_{d b}\right)+\dot{Q}_{\text {sys }}+ \\
& \sum_{j=1}\left(\dot{m}_{d a}^{(j), i n} \cdot h^{(j), \text { in }}+\dot{m}_{d i f f, v}^{(j), \text { in }} \cdot\left(1+W^{(j), \text { in }}\right) \cdot h_{v}^{(j), \text { in }}\right)_{\text {inlets }}+ \\
& \dot{m}_{w}^{s r c} \cdot h_{w}- \\
& \sum_{j=1}\left(\dot{m}_{d a}^{(j), \text { out }} \cdot h+\dot{m}_{d i f f, v}^{(j), \text { out }} \cdot(1+W) \cdot h_{v}\right)_{\text {outlets }}+ \\
& \sum_{j=1}\left(\dot{m}_{t}^{(j), \text { in }} g \cdot z^{(j), \text { in }}\right)_{\text {inlets }}-\sum_{j=1}\left(\dot{m}_{t}^{(j), \text { out }} g \cdot z^{(j), \text { out }}\right)_{\text {outlets }}
\end{aligned}
$$

Looking at the right hand side of equation (38), the term $\dot{Q}_{c o n v}\left(T_{d b}\right)$ is the convective heat rate into the wet air. It depends on the temperatures of the boundary surfaces, their convective heat transfer coefficients and on the $T_{d b}$ of the zone itself. Since we are focusing on the zone dynamics, this last dependency has been pointed out explicitly in the notation. The $\dot{Q}_{\text {sys }}$ is the convective heat added to the wet air by an HVAC system. The third and the fifth terms account for the contribution of incoming and outgoing energy flows respectively. The fourth term $\dot{m}_{w}^{s r c}$ accounts for the energy associated 
with adding or removing (positive or negative respectively) liquid water. Finally the last two terms account the incoming and outgoing potential energy respectively.

The energy balance equation (37) must be expressed as a function of the zone dynamical state coordinates. Let us explore the expression for the left hand side derivative. On one hand, the time derivative of the zone internal energy content, can be expressed as:

$$
\begin{aligned}
\frac{d U}{d t}\left(W_{r e f}, T_{d b}, m_{d a}\left(W, T_{d b}, C T E_{P t}\right)\right) & =\dot{U}\left(x_{1}, x_{2}, m_{d a}\left(x_{1}, x_{2}, x_{3}\right)\right)= \\
& =\frac{\partial U}{\partial x_{1}} \cdot \dot{x}_{1}+\frac{\partial U}{\partial x_{2}} \cdot \dot{x}_{2}+\frac{\partial U}{\partial m_{d a}} \cdot \dot{m}_{d a}
\end{aligned}
$$

Using equation(22) the partial derivatives are:

$$
\begin{gathered}
\frac{\partial U}{\partial W}=\frac{\partial U}{\partial x_{1}}\left(x_{1}, x_{2}, x_{3}\right)=m_{a s}\left(x_{1}, x_{2}, x_{3}\right) \cdot\left(\Delta U+C_{v, v} \cdot x_{2}\right) \\
\frac{\partial U}{\partial T_{d a}}=\frac{\partial U}{\partial x_{2}}\left(x_{1}, x_{2}, x_{3}\right)=m_{d a}\left(x_{1}, x_{2}, x_{3}\right) \cdot\left(C_{v, d a}+C_{v, v} \cdot x_{1}\right) \\
\frac{\partial U}{\partial m_{d a}}=\frac{\partial U}{\partial m_{d a}}\left(x_{1}, x_{2}\right)=\left(C_{v, d a}+x_{1} \cdot C_{v, v}\right) \cdot x_{2}+x_{1} \cdot \Delta U \\
\dot{U}=\frac{\partial U}{\partial x_{1}} \cdot \dot{x}_{1}+\frac{\partial U}{\partial x_{2}} \cdot \dot{x}_{2}+\frac{\partial U}{\partial m_{d a}} \cdot\left[\frac{\partial m_{d a}}{\partial x_{1}} \cdot \dot{x}_{1}+\frac{\partial m_{d a}}{\partial x_{2}} \cdot \dot{x}_{2}+\frac{\partial m_{d a}}{\partial x_{3}} \cdot \dot{x}_{3}\right] \\
\frac{\partial m_{d a}}{\partial x_{1}}=-\frac{x_{3} \cdot M_{v}}{x_{2} \cdot\left(\left(M_{v} / M_{d a}\right)+x_{1}\right)^{2}} \\
\frac{\partial m_{d a}}{\partial x_{2}}=-\frac{x_{3} \cdot M_{v}}{x_{2}^{2} \cdot\left(M_{v} / M_{d a}+x_{1}\right)} \\
\frac{\partial m_{d a}}{\partial x_{3}}=\frac{M_{v}}{x_{2} \cdot\left(M_{v} / M_{d a}+x_{1}\right)}
\end{gathered}
$$

Reorganizing:

$\dot{U}=\left(\frac{\partial U}{\partial x_{1}}+\frac{\partial U}{\partial m_{d a}} \cdot \frac{\partial m_{d a}}{\partial x_{1}}\right) \cdot \dot{x}_{1}+\left(\frac{\partial U}{\partial x_{2}}+\frac{\partial U}{\partial m_{d a}} \cdot \frac{\partial m_{d a}}{\partial x_{2}}\right) \cdot \dot{x}_{2}+\frac{\partial U}{\partial m_{d a}} \cdot \frac{\partial m_{d a}}{\partial x_{3}} \cdot \dot{x}_{3}$ 
The zone wet air potential energy is given by:

$$
U_{p o t}=m_{d a} \cdot g \cdot z_{G, d a}+m_{v} \cdot g \cdot z_{G, v}=m_{d a} \cdot g \cdot\left(z_{G, d a}+W_{r e f} \cdot z_{G, v}\right)
$$

By $z_{G}$ we refer to the center of gravity of the mass. For instance, the center of mass of a zone like zone-I in figure (4) in relative coordinates, is:

$$
c_{G, M}=\frac{c_{u}}{2}\left(1-\frac{c_{u}}{6 H_{M}\left(T_{d b}\right)}\right)
$$

Equation (45) is an example which shows that the position of the center of gravity does depend on the type of species and on the temperature. However, despite the presence of the height scale $H_{M}\left(T_{d b}\right)$, this coordinate hardly varies for practical zone shapes and it may be considered as constant. In order to simplify the small contribution of the potential energy, a common and constant value of $z_{G}$ for both components has been assumed here. Thus, the change in the potential energy is due exclusively to the change of the zone mass content:

$\frac{d U_{p o t}}{d t}=\dot{U}_{p o t}=\frac{d\left(m_{d a}(1+W) \cdot g \cdot z_{G}\right)}{d t}=\left(\frac{d m_{d a}}{d t}(1+W)+m_{d a} \frac{d W}{d t}\right) \cdot g \cdot z_{G}$

Finally adding the results the time derivative of the total zone energy can be expressed in terms of the zone state variables as:

$$
\begin{aligned}
\dot{E}_{\text {total }}= & \left(\frac{\partial U}{\partial x_{1}}+\left(\frac{\partial U}{\partial m_{d a}}+\left(1+x_{1}\right) g z_{G}\right) \cdot \frac{\partial m_{d a}}{\partial x_{1}}+m_{d a} g z_{G}\right) \cdot \dot{x}_{1}+ \\
& \left(\frac{\partial U}{\partial x_{2}}+\left(\frac{\partial U}{\partial m_{d a}}+\left(1+x_{1}\right) g z_{G}\right) \cdot \frac{\partial m_{d a}}{\partial x_{2}}\right) \cdot \dot{x}_{2}+ \\
& \left(\frac{\partial U}{\partial m_{d a}}+\left(1+x_{1}\right) g z_{G}\right) \frac{\partial m_{d a}}{\partial x_{3}} \cdot \dot{x}_{3}
\end{aligned}
$$




\subsection{Mass balance of dry air.}

The dry air mass balance is written as:

$$
\dot{m}_{d a}=\frac{d m_{d a}}{d t}=\sum_{j=1}\left(\dot{m}_{d a}^{(j), \text { in }}\right)_{\text {inlets }}-\sum_{j=1}\left(\dot{m}_{d a}^{(j), \text { out }}\right)_{\text {outlets }}
$$

Using equation (22), equation(48) is rewritten as:

$\frac{\partial m_{d a}}{\partial x_{1}} \cdot \dot{x}_{1}+\frac{\partial m_{d a}}{\partial x_{2}} \cdot \dot{x}_{2}+\frac{\partial m_{d a}}{\partial x_{3}} \cdot \dot{x}_{3}=\sum_{j=1}\left(\dot{m}_{d a}^{(j), i n}\right)_{\text {inlets }}-\sum_{j=1}\left(\dot{m}_{d a}^{(j), \text { out }}\right)_{\text {outlets }}$

\subsection{Mass balance of water.}

When posing the water mass balance, it is assumed that water can only be in vapour phase inside our zone model, although it can be removed or added in liquid phase $\left(\dot{m}_{w}^{s r c}\right.$ negative or positive respectively). In more informal words, our model only sees the gas phase. One advantage of doing so is that it will allow us to deal with the saturation conditions as it will be shown. The balance is written as:

$$
\begin{aligned}
\frac{d m_{v}}{d t}= & \frac{d\left(m_{d a} W_{r e f}\right)}{d t}=\dot{m}_{w}^{\text {src }}+\sum_{j=1}\left(\dot{m}_{v}^{(j), \text { in }}\right)_{\text {inlets }}-\sum_{j=1}\left(\dot{m}_{v}^{(j), \text { out }}\right)_{\text {outlets }}+\dot{m}_{v, \text { sys }}= \\
= & \dot{m}_{w}^{\text {src }}+\sum_{j=1}\left(\dot{m}_{d a}^{(j), \text { in }} W^{(j), \text { in }}\right)_{\text {inlets }}-\sum_{j=1}\left(\dot{m}_{d a}^{s} W\right)_{\text {outlets }}+ \\
& \sum_{j=1}\left(\dot{m}_{d i f f, v}^{(j), \text { in }}\left(1+W^{(j), \text { in }}\right)\right)_{\text {inlets }}-\sum_{j=1}\left(\dot{m}_{\text {diff, }}^{(j), \text { out }}(1+W)\right)_{\text {outlets }}+ \\
& \dot{m}_{v, \text { sys }}
\end{aligned}
$$

As mentioned in section 3.2 the specific humidity may be assumed spatially uniform, although taking into account its distribution is also possible in the 
model. Therefore absolute humidity at the outlet is just $W^{s}=W_{\text {ref }}=W=$ $x_{1}$. Recall that the term $\dot{m}_{w}^{s r c}$, when positive, means that liquid water from any source is added to the wet air and transforms into water vapour while when negative, water is removed but in liquid state. The second and third terms are the conventional convective mass flows of water vapour used in psychrometry. The fourth and fifth terms are the diffusive mass flow rates of water vapour. Finally, the last term, represents the action of some HVAC system.

The left hand side derivative can be written as:

$$
\frac{d m_{v}}{d t}=\frac{d\left(m_{d a} W_{r e f}\right)}{d t}=\frac{d m_{d a}}{d t} \cdot W_{r e f}+m_{d a} \frac{d W_{r e f}}{d t}=\dot{m}_{d a} \cdot x_{1}+m_{a s} \cdot \dot{x}_{1}
$$

By employing equation (22):

$$
\frac{d m_{v}}{d t}=\left(\frac{\partial m_{d a}}{\partial x_{1}} \cdot \dot{x}_{1}+\frac{\partial m_{d a}}{\partial x_{2}} \cdot \dot{x}_{2}+\frac{\partial m_{d a}}{\partial x_{3}} \cdot \dot{x}_{3}\right) \cdot x_{1}+m_{d a} \cdot \dot{x}_{1}
$$

Finally reorganizing the following equation is obtained:

$$
\frac{d m_{v}}{d t}=\left(x_{1} \cdot \frac{\partial m_{d a}}{\partial x_{1}}+m_{a s}\right) \cdot \dot{x}_{1}+\left(x_{1} \cdot \frac{\partial m_{d a}}{\partial x_{2}}\right) \cdot \dot{x}_{2}+\left(x_{1} \cdot \frac{\partial m_{d a}}{\partial x_{3}}\right) \cdot \dot{x}_{3}
$$

\subsection{System of ordinary differential equations for the zone.}

Based on the previous sections, the following system of differential equations can be written for each zone:

$$
\begin{array}{ll}
a_{11} \cdot \dot{x}_{1}+a_{12} \cdot \dot{x}_{2}+a_{13} \cdot \dot{x}_{3}=b_{1} & ,(\text { mass of water }) \\
a_{21} \cdot \dot{x}_{1}+a_{22} \cdot \dot{x}_{2}+a_{23} \cdot \dot{x}_{3}=b_{2} & ,(\text { energy }) \\
a_{31} \cdot \dot{x}_{1}+a_{32} \cdot \dot{x}_{2}+a_{33} \cdot \dot{x}_{3}=b_{3} & ,(\text { mass of dry air })
\end{array}
$$

The coefficients $a$ are functions of the state coordinates $\left\{x_{1}, x_{2}, x_{3}\right\}$. The derivatives $\left\{\dot{x}_{1}, \dot{x}_{2}, \dot{x}_{3}\right\}$ are easily found since equations (54) are linear. There- 
fore the system (54) can be rewritten as:

$$
\begin{aligned}
\frac{d W_{\text {ref }}}{d t} & =\dot{x}_{1}=f_{1}\left(x_{1}, x_{2}, x_{3}, b_{1}, b_{2}, b_{3}\right) \\
\frac{d T_{d b}}{d t} & =\dot{x}_{2}=f_{2}\left(x_{1}, x_{2}, x_{3}, b_{1}, b_{2}, b_{3}\right) \\
\frac{d C T E_{P t}}{d t} & =\dot{x}_{3}=f_{3}\left(x_{1}, x_{2}, x_{3}, b_{1}, b_{2}, b_{3}\right)
\end{aligned}
$$

The coefficients are given by:

$$
\begin{aligned}
a_{11}\left(x_{1}, x_{2}, x_{3}\right) & =x_{1} \cdot \frac{\partial m_{a s}}{\partial x_{1}}+m_{a s} \\
a_{12}\left(x_{1}, x_{2}, x_{3}\right) & =x_{1} \cdot \frac{\partial m_{a s}}{\partial x_{2}} \\
a_{13}\left(x_{1}, x_{2}, x_{3}\right) & =x_{1} \cdot \frac{\partial m_{a s}}{\partial x_{3}} \\
a_{21}\left(x_{1}, x_{2}, x_{3}\right) & =\frac{\partial U}{\partial x_{1}}+\left(\frac{\partial U}{\partial m_{a s}}+\left(1+x_{1}\right) g z_{G}\right) \cdot \frac{\partial m_{a s}}{\partial x_{1}} \\
a_{22}\left(x_{1}, x_{2}, x_{3}\right) & =\frac{\partial U}{\partial x_{2}}+\left(\frac{\partial U}{\partial m_{a s}}+\left(1+x_{1}\right) g z_{G}\right) \cdot \frac{\partial m_{a s}}{\partial x_{2}} \\
a_{23}\left(x_{1}, x_{2}, x_{3}\right) & =\left(\frac{\partial U}{\partial m_{d a}}+\left(1+x_{1}\right) g z_{G}\right) \frac{\partial m_{a s}}{\partial x_{3}} \\
a_{31}\left(x_{1}, x_{2}, x_{3}\right) & =\frac{\partial m_{a s}}{\partial x_{1}} \\
a_{32}\left(x_{1}, x_{2}, x_{3}\right) & =\frac{\partial m_{a s}}{\partial x_{2}} \\
a_{33}\left(x_{1}, x_{2}, x_{3}\right) & =\frac{\partial m_{a s}}{\partial x_{3}}
\end{aligned}
$$

The terms $b$, represent the excitations of the zone. The different zones are coupled with each other through the $\left\{b_{1}, b_{2}, b_{3}\right\}$, due to the flows (convective or diffusive) and heat. In concrete, heat coupling with the boundary solids or a convective HVAC system, appear in these terms as $\dot{Q}_{c o n v}$ and $\dot{Q}_{\text {sys }}$ 
respectively.

$$
\begin{aligned}
b_{1}= & \dot{m}_{w}^{\text {src }}+\sum_{j=1}\left(\dot{m}_{d a}^{(j), \text { in }} x_{1}^{(j), \text { in }}\right)_{\text {inlets }}-\sum_{j=1}\left(\dot{m}_{d a}^{(j), \text { out }} \cdot x_{1}\right)_{\text {outlets }}+ \\
& \sum_{j=1}\left(\dot{m}_{d i f f, v}^{(j), \text { in }}\left(1+x_{1}^{(j), \text { in }}\right)\right)-\sum_{j=1}\left(\dot{m}_{d i f f, v}^{(j), \text { out }}\left(1+x_{1}\right)\right)_{\text {outlets }}+ \\
& \dot{m}_{v, \text { sys }},(\text { mass of water }) \\
b_{2}= & \dot{Q}_{\text {conv }}\left(T_{d b}\right)+\dot{Q}_{\text {sys }}+ \\
& \sum_{j=1}\left(\dot{m}_{d a}^{(j), \text { in }} \cdot h^{(j), \text { in }}+\dot{m}_{d i f f, v}^{(j), \text { in }}\left(1+x_{1}^{(j), \text { in }}\right) \cdot h_{v}^{(j)}\right)_{\text {inlets }}+ \\
& \dot{m}_{w}^{\text {src }} \cdot h_{w}- \\
& \sum_{j=1}\left(\dot{m}_{d a}^{(j), \text { out }} \cdot h\left(h_{1}, x_{2}\right)+\dot{m}_{d i f f, v}^{(j), \text { out }} \cdot\left(1+x_{1}\right) \cdot h_{v}\left(x_{2}\right)\right)_{\text {outlets }}+ \\
& \sum_{j=1}\left(\dot{m}_{t}^{(j), \text { in }} g \cdot z^{(j), \text { in }}\right)_{\text {inlets }}-\sum_{j=1}\left(\dot{m}_{t}^{(j), \text { out }} g \cdot z^{(j), \text { out }}\right)_{\text {outlets }},(\text { energy }) \\
b_{3}= & \sum_{j=1} \dot{m}_{d a}^{(j), \text { in }}-\sum_{j=1} \dot{m}_{d a}^{(j), \text { out }},(\text { mass of dry air })
\end{aligned}
$$

In equation (57b) the dependence of the specific enthalpy on state variables is shown explicitly as $h\left(x_{1}, x_{2}\right)$ and $h_{v}\left(x_{2}\right)$. This amount depends on the dry bulb temperature $x_{2}$ and the specific humidity $x_{1}$.

Our zone model does not consider the possibility of a mixture of wet air and liquid water (like mist). Therefore, whenever the saturation conditions are reached, the excess of water transforms into liquid state and is removed. In other words, the wet air state should follow a saturation trajectory as a constrain. In Appendix $\mathrm{A}$ it is explained how to modify the model to deal with wet air saturation. The result of the analysis is that the system of 
ordinary differential equations (55) must be modified as follows:

$$
\begin{aligned}
& \dot{x}_{1}=f_{1}\left(x_{1}, x_{2}, x_{3}, b_{1}, b_{2}, b_{3}, \alpha_{\text {control }}\right) \\
& \dot{x}_{2}=f_{2}\left(x_{1}, x_{2}, x_{3}, b_{1}, b_{2}, b_{3}, \alpha_{\text {control }}\right) \\
& \dot{x}_{3}=f_{3}\left(x_{1}, x_{2}, x_{3}, b_{1}, b_{2}, b_{3}, \alpha_{\text {control }}\right)
\end{aligned}
$$

In system (58), the $\alpha_{\text {control }}$ is an artificial control introduced to keep the mixture saturated and which acts according to the following logic (see the details in Appendix A):

1. Calculate $P_{v, \text { sat }}$ using equation (26) with the current $x_{2}$ value.

2. Calculate the current water vapour pressure as:

$$
P_{v}\left(x_{1}, x_{3}\right)=x_{3} \cdot \frac{R}{V} \cdot \frac{x_{1}}{\left(\frac{M_{v}}{M_{d a}}+x_{1}\right)}
$$

3. If $P_{v} \geq P_{v, s a t}$ then the results from Appendix A should be applied. The $\alpha$ is a rate of water addition computed using equation (A.8). Remark: notice that the over-saturation is checked at the zone reference level and this represents an approximation, below that level there would be over-saturation and above that level the air is not saturated yet.

4. If the previous item is true then $\alpha<0$ meaning that a control action is needed to avoid moving into an over-saturated state. If no action is taken then the system will start moving away from saturation into an over-saturation state. The control action is computed as $\alpha_{\text {control }}$ (equation (A.9)). The $\alpha_{\text {control }}$ acts on $b$ terms and a new set is computed with equations (A.3).

5. Proceed with the numerical integration of the original system of equations. 


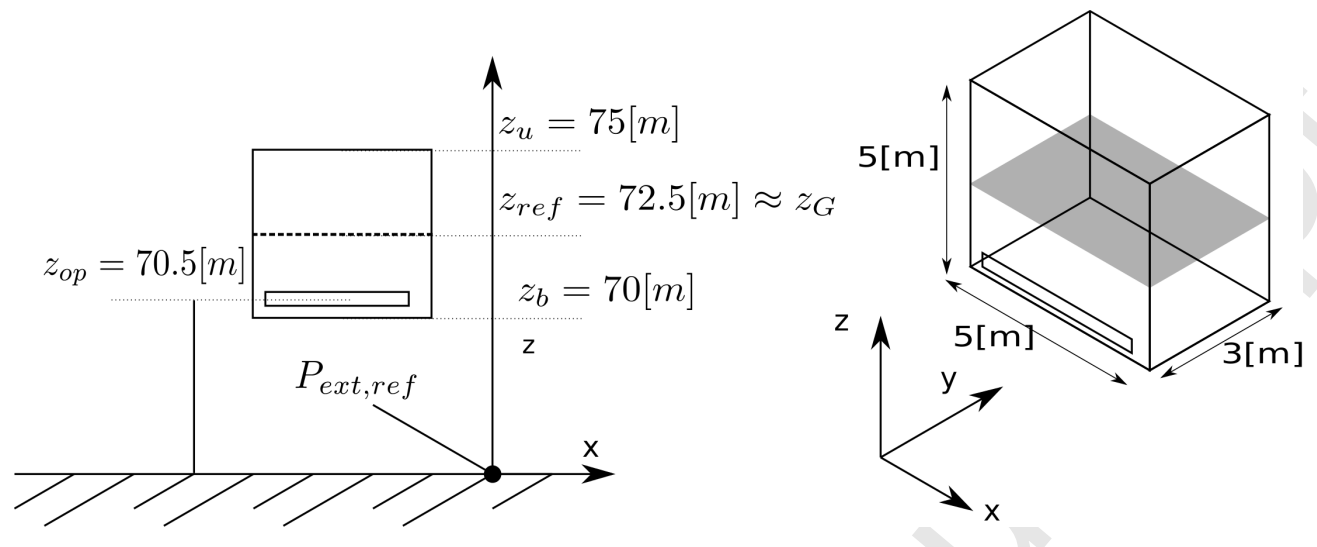

Figure 6: Example zone.

\section{Example}

This section illustrates the outcomes from the proposal using a very simplified model which consist of one zone and one opening so that mass flow rate is one-way (in or out). Despite its simplicity some models from the literature (see section 1) would have difficulties to simulate such a case, since they whether impose a constant air mass or quasi-steady conditions or a constant total pressure and air density. The whole problem is made up of just two zones; one corresponds to the outside conditions and acts in practice as a forcing function, the other is just the zone with the sought dynamics (see figure (6)). The characteristics of the problem and hypothesis, for this simple example, are the following:

- The zone has a volume of $V=5 \times 5 \times 3=75\left[\mathrm{~m}^{3}\right]$.

- It is placed $70[\mathrm{~m}]$ above the sea level (see the details of the levels in figure (6)).

- Assume that the center of gravity $z_{G}$ is practically equal to the reference 
absolute height $z_{\text {ref }}$, due to the small variation of the density within the zone.

- It has a small opening at the bottom with an area $A_{o p}=0.001\left[\mathrm{~m}^{2}\right]$ (magnified in the figure). (note: A small area was used to amplify the pressure effects.)

- For simplicity, any solar or infrared radiation heat exchange is not considered.

- The walls, roof and floor have a negligible mass and a global heat transfer coefficient of $1.5\left[\mathrm{Wm}^{-2} \mathrm{~K}^{-1}\right]$ including conduction and the outside/inside convection heat transfer coefficients. Thus the convective heat transfer in the zone is given by:

$$
\begin{aligned}
\dot{Q}_{c o n v}(t) & =(2(5 \times 5)+4(5 \times 3)) \cdot 1.5 \cdot\left(T_{d b, \text { ext }}-T_{d b}(t)\right) / 1000= \\
& =A_{\text {zone }} \cdot 1.5 \cdot\left(T_{d b, \text { ext }}-x_{2}(t)\right) / 1000 \quad,[k W]
\end{aligned}
$$

The thickness of any boundary wall is $e_{\text {wall }}=0.20[\mathrm{~m}]$.

- We have chosen two HVAC systems to illustrate the behaviour of the model.

System (A) acts according to:

$$
\dot{Q}_{\text {sys }}(t)=\left\{\begin{aligned}
-4[k W] & , t<900[s](15 \text { minutes }) \\
5[k W] & , 900<t<2100[s](20 \text { minutes }) \\
0[k W] & , \text { otherwise }
\end{aligned}\right.
$$

Its goal is to force saturation conditions. 
System (B) represents a (heating or cooling) coil with by-pass factor $B F=0.15$, apparatus temperature dew point $T_{a d p}=9\left[{ }^{\circ} C\right]$, dry air mass rate moving across the coil $\dot{m}_{d a, c o i l}=0.6\left[\mathrm{~kg}_{d a} \mathrm{~s}^{-1}\right]$ and coil ideal conditions $h_{\text {coil }}\left(x_{3}(t), T_{a d p}\right)$ and $W_{\text {coil }}\left(x_{3}(t), T_{a d p}\right)$. It acts according to:

$$
\dot{Q}_{s y s}(t)=\left\{\begin{aligned}
& \dot{m}_{d a, \text { coil }} \cdot(1-B F) \cdot\left(h_{\text {coil }}(t)-h\left(x_{1}(t), x_{2}(t)\right)\right), t<900[s] \\
& 5[k W], 900<t<2100[s] \\
& 0[k W], \text { otherwise }
\end{aligned}\right.
$$$$
\dot{m}_{v, \text { sys }}(t)=\left\{\begin{array}{r}
\text { if } P_{v}^{s a t}\left(T_{a d p}\right)<P_{v}\left(x_{1}(t), x_{3}(t)\right) \text { then } \\
\dot{m}_{d a, \text { coil }} \cdot(1-B F) \cdot\left(W_{\text {coil }}(t)-x_{1}(t)\right) \\
\text { else } \\
0.0 \quad, t<900[s] \\
5[k W] \quad, 900<\quad<\quad<2100[s] \\
0[k W], \text { otherwise }
\end{array}\right.
$$

therefore in either case, cooling lasts 15 minutes from the beginning, afterwards there is heating during 20 minutes and finally everything is switched off.

- The pressure at sea level, which is the reference level for the outside zone, is $P_{\text {ext,ref }}=101325[\mathrm{~Pa}]$. The external temperature is spatially uniform $T_{d b, e x t}=25\left[{ }^{\circ} \mathrm{C}\right]$. The profile is $P_{\text {ext }}(z)=P_{\text {ext,ref }}-g \cdot 1.152$. $(1+0.0171) \cdot z[P a]$. The relative humidity is $\phi_{\text {ext }}=85 \%$. There is no wind.

- The zone is initially in total pressure and temperature equilibrium with the outside conditions; $P_{r e f}=100494.135[\mathrm{~Pa}], T_{d b, e x t}=25\left[{ }^{\circ} \mathrm{C}\right]$, but has 
a smaller relative humidity $\phi_{\text {ref }}=50 \%$.

- The water vapour diffusion coefficient in air is given (see [4]) by:

$$
\delta_{v}(T, P)=2 \cdot 10^{-7} \cdot \frac{T^{0.81}}{P} \quad,\left[k g_{H_{2} O} \cdot m^{-1} \cdot s^{-1} \cdot P a^{-1}\right]
$$

with $T[K]$ and $P[P a]$ mixture pressure. Therefore the diffusivity flow of water vapour using an estimation of the vapour pressure gradient across the opening is:

$$
\begin{cases}\frac{d P_{v}}{d x}\left(z_{o p}\right) \approx \frac{\left(P_{v}\left(z_{o p}\right)-P_{v, \text { ext }}\left(z_{o p}\right)\right)}{e_{w a l l}} & \\ \dot{m}_{d i f f, v}^{s,(j)}=A_{o p} \cdot \delta_{v}\left(T_{d b}, P\left(z_{o p}\right)\right) \cdot d P_{v} / d x\left(z_{o p}\right) & , \text { if } d P_{v} / d x>0 \text { (outgoing) } \\ \dot{m}_{d i f f, v}^{e,(j)}=A_{o p} \cdot \delta_{v}\left(T_{d b, e x t}, P_{e x t}\left(z_{o p}\right)\right) \cdot d P_{v} / d x\left(z_{o p}\right) & , \text { if } d P_{v} / d x<0 \text { (incoming) }\end{cases}
$$

- The convective volumetric flows of wet air are given by the well-known equation:

$$
\dot{V}=C_{d} \cdot A_{o p} \cdot\left(2 \cdot \frac{|\Delta P|}{\rho}\right)^{0.66} \quad,\left[m^{3} \cdot s^{-1}\right]
$$

where $\rho\left[\mathrm{kg} \cdot \mathrm{m}^{-3}\right]$ is density of the mixture and $\Delta P[P a]$ is the total pressure difference across the orifice. If a plane orifice is assumed then the discharge coefficient is $C_{d}=0.61$.

\section{Example results}

The example model of section 4 has been programmed in Scilab [32], although as said in the introduction, the final goal is to use a DEVS model. The solution method employed has been the ode() function which uses the ODEPACK package from A. C. Hindmarsh [33]. The fixed time employed is $\Delta t=1[s]$. Much bigger time steps can be used without affecting the 
stability. By doing so, the main difference appears in the response of the pressure because is the fastest signal.

Figure (7) shows the results for the HVAC system (A). The initial mass of dry air inside the room is $m_{d a}(0)=86.67[\mathrm{~kg}]$. At the start $(t=0)$ the cooling system is on, causing the $T_{d b}$ to decrease. This in turn causes the zone pressure to decrease and outside air flows into the room. As the outside air has higher specific humidity than the zone, it rises slightly from $W=10.0$ to $W=10.2\left[g_{\mathrm{H}_{2} \mathrm{O}} \cdot k g_{d a}^{-1}\right]$.

After around four minutes from start, zone wet air saturation conditions are reached. Notice that the amount of dry air mass has risen from its initial value up to $89.8[\mathrm{~kg}]$. The dew temperature at that moment is $T_{\text {dew }}=$ $14.3\left[{ }^{\circ} \mathrm{C}\right]$. After that point the dry and dew temperatures must be equal, that means that the control $\alpha_{\text {control }}$ is acting. The action of the control implies that the zone now has in fact two degrees of freedom. Under this control action and while cooling is on, water is being removed from the wet air (see upper curve in figure $(7)$ ), the $T_{d b}$ decreases at a lower rate than before reaching the saturation conditions and dry air mass keeps flowing into the room. When heating starts at $t=15[\mathrm{~min}]$ the wet air moves away from saturation and $\alpha_{\text {control }}$ is off.

At the end of the cooling process the total amount of zone dry air mass is $\approx 92.3[\mathrm{~kg}]$ and the temperature is as low as $T_{d b}=T_{\text {dew }}=8.7\left[^{\circ}\right]$. An increase of around $6[\mathrm{~kg}]$ of zone dry air mass from the beginning.

The reference pressure increases just after the heater is switched on. The heating lasts $t=20[\mathrm{~min}]$. The zone air mass is reduced and the $T_{d b}$ rises. The zone specific humidity does not change. 
Finally when the heater is switched off the zone is at $T_{d b}=53\left[{ }^{\circ} \mathrm{C}\right]$ while the outside air is at $T_{d b, e x t}=25\left[{ }^{\circ} \mathrm{C}\right]$.

Now starts the process of zone relaxation towards a thermodynamic equilibrium with the outside air.

Due to the big temperature difference between the zone air and the outside air, there is a high outgoing conduction heat transfer rate. This makes the total pressure go down abruptly along with $T_{d b}$ and the zone is refilled with outside air. Now the outside air is more humid than the zone air, so once more the specific humidity rises.

After a long time there will be an equilibrium of temperature, pressure and humidity between the zone and the outside air. The humidity (not shown) will reach the outside value, but at a low rate, due to the small diffusivity of water vapour through the opening.

(Recall once more that the area of the opening has been chosen small enough to show the effect on the pressure.)

Figure (8) is similar to Figure (7) but for the cooling process. The cooling coil decreases the absolute humidity of the zone, but there is no saturation inside the zone. The cooling coil takes the wet air from the zone and returns the same dry air mass rate but colder and drier.

\section{Conclusions}

The paper has presented a new proposal for a wet air zone model to be used in energy simulation. It was detected that a simplified but complete model was missing which coupled the three phenomena ; dry air, water vapour and heat flow. This model would belong to the set of internal cou- 


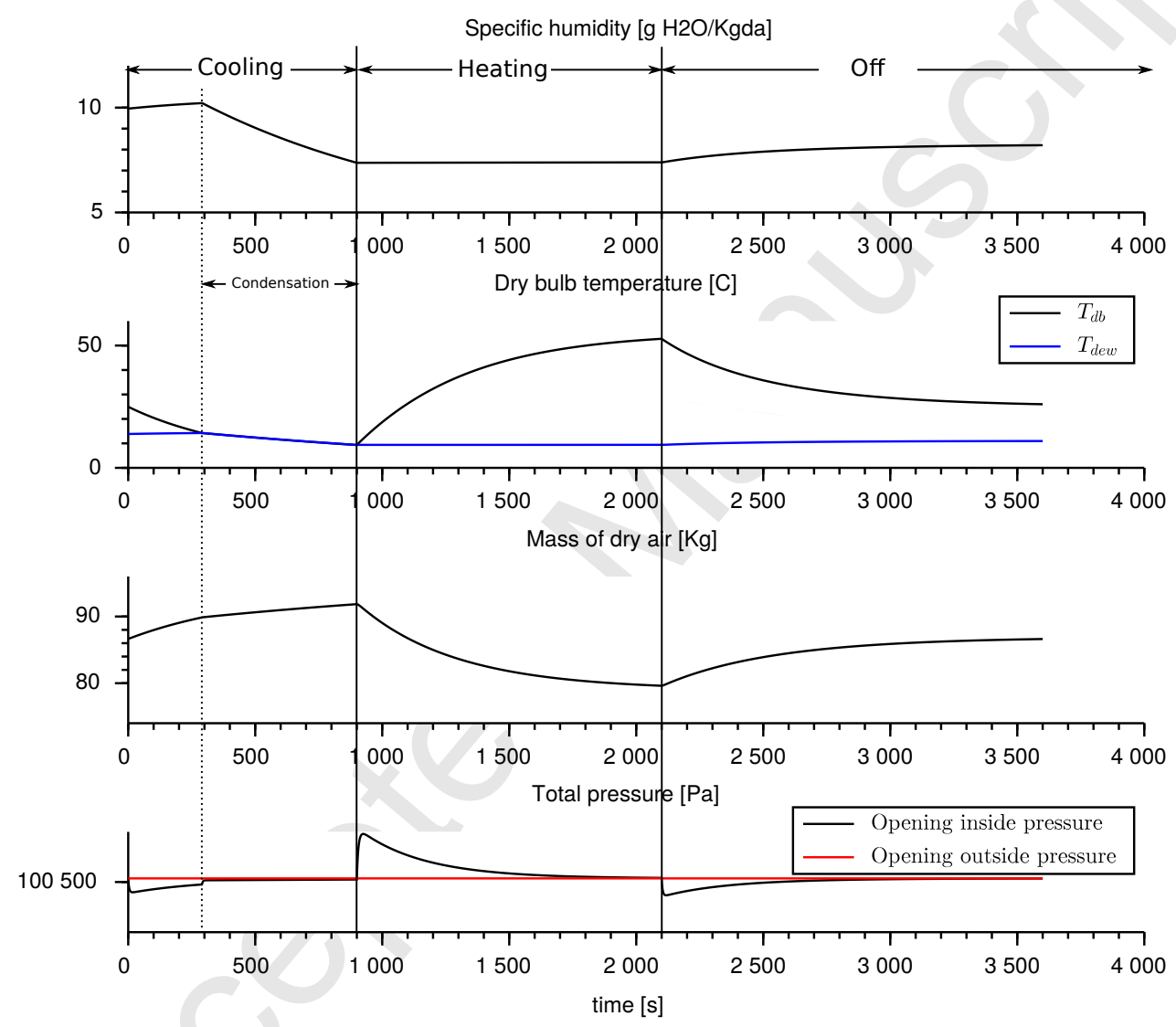

Figure 7: Example of the zone dynamics for HVAC-system (A) to illustrate the saturation control action. Specific humidity is given in $\left[g_{\mathrm{H}_{2} \mathrm{O}} \cdot \mathrm{kg}_{d a}^{-1}\right]$. The dry bulb and dew temperatures are given in $\left[{ }^{\circ} \mathrm{C}\right]$. The mass of dry air is given in $[\mathrm{kg}]$. The total pressure is given in $[P a]$. 


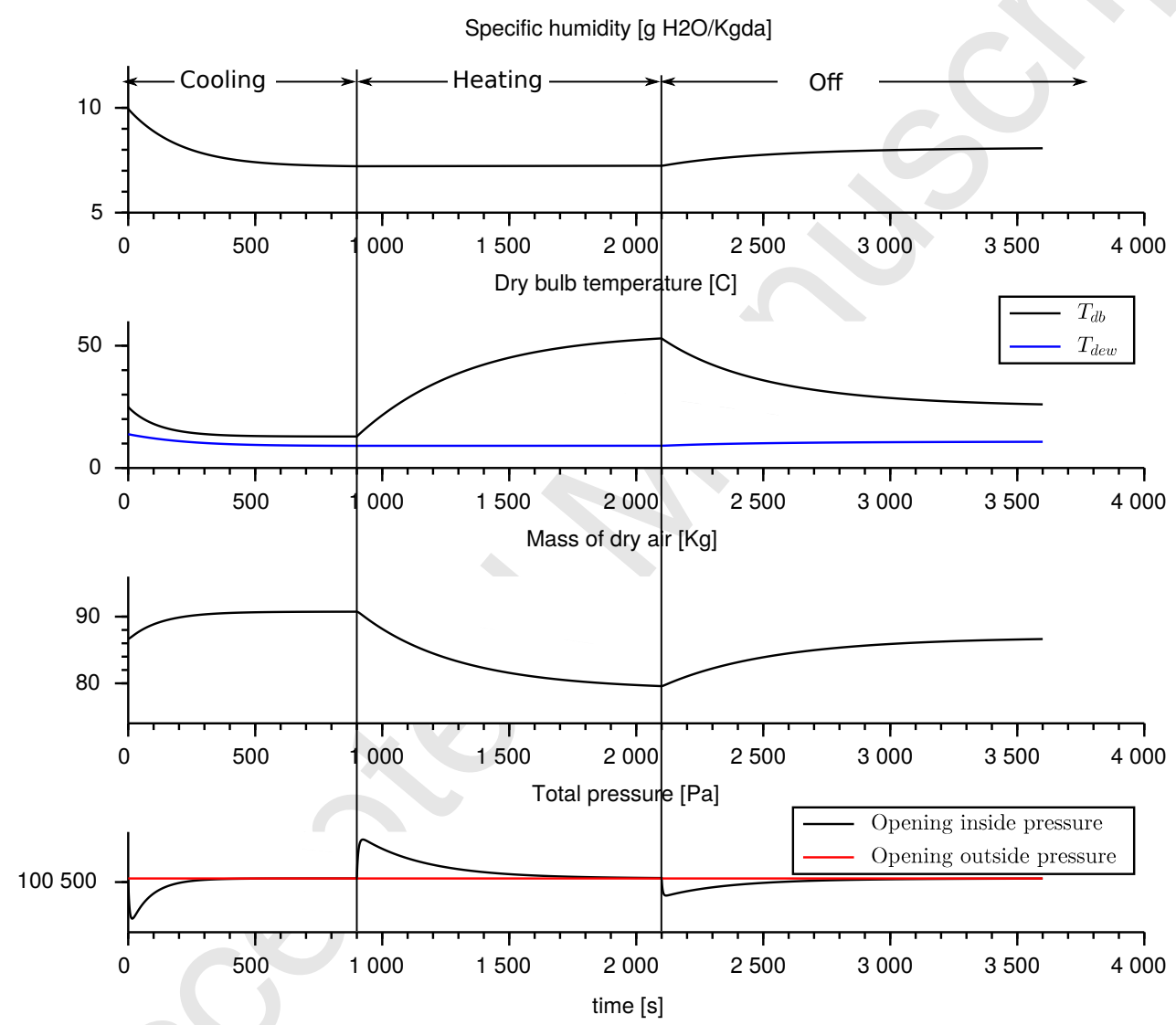

Figure 8: Example of the zone dynamics for HVAC-system (B). Specific humidity is given in $\left[g_{H_{2} \mathrm{O}} \cdot \mathrm{kg}_{d a}^{-1}\right]$. The dry bulb and dew temperatures are given in $\left[{ }^{\circ} \mathrm{C}\right]$. The mass of dry air is given in $[\mathrm{kg}]$. The total pressure is given in $[\mathrm{Pa}]$. 
pling models, according to the classification in [27]. The proposed model is able to deal with saturation conditions. In contrast to other models, the reference level inside the zone cannot be chosen arbitrarily but it is chosen so that the zone mass content can be tracked by the dynamical variables. It depend only, to some extent, on the zone geometrical properties.

The resulting model is made up of three ordinary differential equations. The $b$ terms contain boundary and bulk source or sink terms and an extra parameter $\alpha_{\text {control }}$ is employed to force saturation conditions.

It has also been shown how to link the zone model to a fan-coil HVAC system.

Finally we would like to stress that although it has been solved by traditional methods, the intention is to use the model in DEVS-based methods in order to deal globally with the stiffness issue. This will be discussed in a future paper, extending the results from [17].

\section{Appendix A. Wet air over-saturation.}

The condition for the water vapour to reach saturation is:

$$
P_{v}=P_{v, s a t}\left(x_{2}\right)
$$

where $P_{v, s a t}$ is a function of $x_{2}=T_{d b}$ and can be computed with equation (26), and $P_{v}$ can be obtained from equation (27). When this condition is reached then the specific humidity $x_{1}$ is not an independent state but a function (see Eq. (A.2));

$$
x_{1}^{\text {sat }}=f_{\text {sat }}\left(x_{2}, x_{3}\right)
$$

of the other two ( dry bulb temperature $x_{2}$ and total pressure $x_{3}$ respectively). To force the state of the system to follow the saturation curve, liquid water 
must be removed from the air. Let us call the rate of liquid water removal as $\alpha$. It has the same meaning as $\dot{m}_{w}^{s r c}$ but has the special role of forcing the state trajectory not to cross towards an over saturation state. Thus $\alpha$ should be negative whenever the system tries to enter the over saturation zone and acts like a control. Therefore the independent terms $b$ from equations (57) should be modified accordingly as:

$$
\begin{array}{lrl}
b_{1}^{\text {sat }}=b_{1}+\alpha & , \text { (mass of water vapor balance) } \\
b_{2}^{\text {sat }}=b_{2}+\alpha \cdot h_{w} & \text {, (energy balance) } \\
b_{3}^{\text {sat }}=b_{3} & \text { (mass of dry air) }
\end{array}
$$

The function (A.2) must be employed along with the system of equations (55) leading to a new system:

$$
\begin{aligned}
\dot{x}_{1}^{s a t} & =\frac{\partial f_{\text {sat }}}{\partial x_{2}} \cdot \dot{x}_{2}+\frac{\partial f_{\text {sat }}}{\partial x_{3}} \cdot \dot{x}_{3}=f_{1}\left(x_{1}, x_{2}, x_{3}, b_{1}, b_{2}, b_{3}, \alpha\right) \\
\dot{x}_{2} & =f_{2}\left(x_{1}, x_{2}, x_{3}, b_{1}, b_{2}, b_{3}, \alpha\right) \\
\dot{x}_{3} & =f_{3}\left(x_{1}, x_{2}, x_{3}, b_{1}, b_{2}, b_{3}, \alpha\right)
\end{aligned}
$$

So now, the unknowns are $\left\{x_{2}, x_{3}, \alpha\right\}$. Although it is a non-linear ordinary differential algebraic system of equations, $\alpha$ can be cleared just leaving two non-linear differential ordinary equations. First, it can be shown that:

$$
\begin{aligned}
& \frac{\partial f_{\text {sat }}}{\partial x_{2}}\left(x_{2}, x_{3}\right)=-\frac{M_{v}}{M_{a s}} \cdot \frac{P_{v, s a t}\left(x_{2}\right)}{\left(P_{v, s a t}\right)^{2}-x_{3} \cdot R / V} \cdot \frac{P_{v, s a t}\left(x_{2}\right)}{10} \frac{1779.8175}{\left(x_{2}+237.309\right)^{2}} \\
& \frac{\partial f_{\text {sat }}}{\partial x_{3}}\left(x_{2}, x_{3}\right)=\frac{M_{v}}{M_{a s}} \cdot\left(\frac{P_{v, s a t}\left(x_{2}\right)}{\left(P_{v, s a t}\left(x_{2}\right)-x_{3} \cdot R / V\right)^{2}}\right) \cdot \frac{R}{V}
\end{aligned}
$$

Remark: note that equations (A.5) depend also on the geometrical volume of the zone $V$. 
The expression for $\alpha$ can be obtained by clearing its value from equations (A.4). Some intermediate variables $\left\{i_{1}, i_{2}, i_{3}, \alpha_{1}, \alpha_{2}, \alpha_{3}\right\}$ are used. They are written as a function of the $a^{\prime} s$ from (56) and $b^{\prime} s$ from (57).

$i_{1}=\frac{\partial f_{\text {sat }}}{\partial x_{2}} \cdot\left\{a_{11} b_{2} a_{33}+a_{21} b_{3} a_{13}+b_{1} a_{23} a_{31}-\left(a_{13} b_{2} a_{31}+b_{1} a_{12} a_{33}+a_{23} b_{3} a_{11}\right)\right\}$

$i_{2}=\frac{\partial f_{\text {sat }}}{\partial x_{3}} \cdot\left\{a_{11} a_{22} b_{3}+a_{21} a_{32} b_{1}+a_{12} b_{2} a_{31}-\left(b_{1} a_{22} a_{31}+a_{12} a_{21} b_{3}+b_{2} a_{32} a_{11}\right)\right\}$

$i_{3}=\left\{b_{1} a_{22} a_{33}+b_{2} a_{32} a_{13}+a_{12} a_{23} b_{3}-\left(a_{13} a_{22} b_{3}+a_{12} b_{2} a_{33}+a_{23} a_{32} b_{1}\right)\right\}$

, and;

$$
\begin{aligned}
& \alpha_{1}=\frac{\partial f_{\text {sat }}}{\partial x_{2}} \cdot\left\{a_{11} a_{33} h_{w}+a_{23} a_{31}-\left(a_{13} a_{31} h_{w}+a_{21} a_{33}\right)\right\} \\
& \alpha_{2}=\frac{\partial f_{\text {sat }}}{\partial x_{3}} \cdot\left\{a_{21} a_{32}+a_{12} h_{w} a_{31}-\left(a_{22} a_{31}+a_{32} a_{11} h_{w}\right)\right\} \\
& \alpha_{3}=\left\{a_{22} a_{33}+a_{32} a_{13} h_{w}-\left(a_{12} a_{33} h_{w}+a_{23} a_{32}\right)\right\}
\end{aligned}
$$

Finally:

$$
\alpha=-\frac{i_{1}+i_{2}+i_{3}}{\alpha_{1}+\alpha_{2}+\alpha_{3}} \quad\left[k g_{H_{2} O} \cdot s^{-1}\right]
$$

So this $\alpha$ would be the right rate of liquid water removal from wet air if its state trajectory followed a saturated state path, that is, the equality condition (A.1) is always fulfilled along the path.

It should be pointed out that this $\alpha$ depends on the zone volume.

Nevertheless in practice, the system tends to cross into the over-saturated conditions region and this signal is not enough.

The solution is to modify the control parameter $\alpha$. 
Based on $\alpha$, a new $\alpha_{\text {control }}$ has been used instead. It provides the zone dynamical system with a sort of sliding mode control. The new control parameter adds a correction action proportional to the error $e=P_{v}-P_{v, \text { sat }}$ in the direction of $\alpha$.

$$
\alpha_{\text {control }}=\alpha \cdot\left(1+K_{\text {control }} \cdot\left(P_{v}-P_{v, \text { sat }}\left(x_{2}\right)\right)=\alpha \cdot\left(1+K_{\text {control }} \cdot e\right)\right.
$$

Several try and error tests show that the solution is quite insensible to the value of the gain $K_{\text {control }}$. In practice $K_{\text {control }}=1$ seems to work well.

Therefore whenever saturation conditions are reached by modifying the independent terms $b$ as shown in equations (A.3) with the $\alpha_{\text {control }}$ from equation (A.9), while keeping the same equations (55), the saturated evolution of the zone state can be maintained.

\section{References}

[1] [link].

URL http://www.bfrl.nist.gov/IAQanalysis/CONTAM/

[2] [link].

URL http://epb.1bl.gov/comis/

[3] D. M. D. M. Lorenzetti, C. Wary, Air-handling system modeling in enerenergy:recommendations for meeting stakeholder needs, Tech. rep., Lawrence Berkeley National laboratory (Environmental Energy Technologies Division) (2014).

[4] [link].

URL http://www.wufi.de/index_e.html 
[5] A. Janssens, M. Woloszyn, C. Rode, A. Sasic-Kalagasidis, M. D. Paepe, From EMPD to CFD overview of different approaches for heat air and moisture modeling in iea annex 41, in: IEA ECBCS Closing seminar (Copehagen), 2008.

[6] W. S. Dols, S. J. Emmerich, B. J. Polidoro, Coupling of whole-building energy, airflow and contaminant transport models (energyplus and contam) using co-simulation, National Institute of Standards NIST (2016)doi:http://dx.doi.org/10.1007/s12273-016-0279-2.

URL http://www.nist.gov/manuscript-publication-search.cfm?pub_id=918338

[7] W. S. Dols, S. J. Emmerich, B. J. Polidoro, Coupling the multizone airflow and contaminant transport software contam with energyplus using co-simulation, Building Simulation 9 (4) (2016) 469-479. doi:10.1007/s12273-016-0279-2.

URL http://dx.doi.org/10.1007/s12273-016-0279-2

[8] J. Axley, Multizone airflow modeling in buildings: History and theory, HVAC and R Research 13 (6) (2007) 907-928, cited By 32.

[9] H. Wang, Z. J. Zhai, Advances in building simulation and computational techniques: A review between 1987 and 2014, Energy and Buildings 128 (2016) 319 - 335. doi:http://dx.doi.org/10.1016/j.enbuild.2016.06.080. URL http://www.sciencedirect.com/science/article/pii/S0378778816305692

[10] Y. Chen, L. Gu, J. Zhang, Energyplus and CHAMPS-multizone cosimulation for energy and indoor air quality analysis, Building Simula- 
tion 8 (4) (2015) 371-380. doi:10.1007/s12273-015-0211-1.

URL http://dx.doi.org/10.1007/s12273-015-0211-1

[11] M. Mirsadeghi, Co-simulation of building energy simulation and computational fluid dynamics for whole-building heat, air and moisture engineering, phD. Thesis, Technische Universiteit Eindhoven (2011)

URL http://www.janhensen.nl/team/past/Mirsadeghi.pdf

[12] D. Cóstola, External coupling of building energy simulation and building element heat, air and moisture simulation, phD. Thesis, Technische Universiteit Eindhoven (2011)

URL http://www.janhensen.nl/team/past/Costola.pdf

[13] M. Santamouris, P. Wouters, Building ventilation (state of the art), Earthscan, 2006.

[14] Huang, J., F. Winkelmann, F. Buhl, C. Pedersen, D. Fisher, R. Liesen, R. Taylor, R.Strand, D. Crawley, L. Lawrie Linking The COMIS MultiZone Airflow Model With The ENERGYPLUS Building Energy Simulation Program., Vol. 2 (pp. 1065-1070) of Proceedings of Building Simulation '99.

URL http://www.hvac.okstate.edu/

[15] S. J. Emmerich, W. S. Dols, L. L. Wang, Simultaneous solutions of coupled thermal airflow problem for natural ventilation in buildings, Hvac \& Research 18 (2011) $264-274$.

URL http: //www.nist.gov/manuscript-publication-search. cfm?pub_id=907720 
[16] G. A. Wainer, P. J. Mosterman, Discrete-Event modeling and simulation (Theory and Applications), Computational Analysis, Synthesis, and Design of Dynamic Systems Series, CRC press, 2011.

[17] V. M. S. Frances, E. J. S. Escriva, J. M. P. Ojer, Discrete event heat transfer simulation of a room, International Journal of Thermal Sciences 75 (2014) 105 - 115. doi:http://dx.doi.org/10.1016/j.ijthermalsci.2013.07.024.

URL http://www.sciencedirect.com/science/article/pii/S1290072913001889

[18] J. J. Zhang, W. Feng, J. Grunewald, A. Nicolai, C. Zhang, Champsmultizone - a combined heat, air, moisture and pollutant simulation environment for whole-building performance analysis, HVAC\&R Research 18 (2012) 233-251.

[19] R. Krishna, J. Wesselingh, The maxwell-stefan approach to mass transfer, Chemical Engineering Science 52 (6) (1997) 861 - 911. doi:http://dx.doi.org/10.1016/S0009-2509(96)00458-7.

URL http://www.sciencedirect.com/science/article/pii/S0009250996004587

[20] L. L. Wang, Q. Chen, Evaluation of some assumptions used in multizone airflow network models, Building and Environment 43 (2008) 16711677. doi:10.1016/j.buildenv.2007.10.010.

[21] M. Qin, G. Walton, R. Belarbi, F. Allard, Simulation of whole building coupled hygrothermal-airflow transfer in different climates, Energy Conversion and Management 52 (2011) 14701478. doi:10.1016/j.enconman.2010.10.010. 
[22] J. Berger, S. Guernouti, M. Woloszyn, F. Chinesta, Proper generalised decomposition for heat and moisture multizone modelling, Energy and Buildings $105 \quad$ (2015) $334 \quad-351$. doi:http://dx.doi.org/10.1016/j.enbuild.2015.07.021.

URL http://www.sciencedirect.com/science/article/pii/S0378778815301389

[23] M. Steeman, A. Janssens, H. Steeman, M. V. Belleghem, M. D. Paepe, On coupling 1d non-isothermal heat and mass transfer in porous materials with a multizone building energy simulation model, Building and Environment 45 (2010) 865877. doi:10.1016/j.buildenv.2009.09.006.

[24] F. Tariku, K. Kumaran, P. Fazio, Integrated analysis of whole building heat, air and moisture transfer., International Journal of Heat and Mass Transfer 53 (2010) 31113120. doi:10.1016/j.ijheatmasstransfer.2010.03.016.

[25] F. Tariku, K. Kumaran, P. Fazio, Determination of indoor humidity profile using a whole-building hygrothermal model, Building Simulation 4 (1) (2011) 61-78. doi:10.1007/s12273-011-0031-x.

URL http://dx.doi.org/10.1007/s12273-011-0031-x

[26] L. Mora, Prdiction des performances thermo-erauliques des btiments par association de modles de diffrents niveaux de finesse au sein dun environnement orient objet, Ph.D. thesis, Université de la Rochelle (December 2003).

URL https://tel.archives-ouvertes.fr/tel-00003984

[27] P. Steskens, Modelling of the hygrothermal interactions between the 
indoor environment and the building envelope, Ph.D. thesis, DTU Civil Engineering Department of Civil Engineering Technical University of Denmark (2009).

[28] M. Trocme, B. Peuportier, Studying innovative concepts by coupling simplified: Simulation and multizone airflow model, HAL archivesouvertes.fr (2009) 149-154CISBAT 2009 - Renewables in a changing climate : from nano to urban scale, Sep 2009, Lausanne, Switzerland. URL https: //hal-mines-paristech.archives-ouvertes.fr/hal-00574742

[29] F. Tariku, K. Kumaran, P. Fazio, Transient model for coupled heat, air and moisture transfer through multilayered porous media, International Journal of Heat and Mass Transfer 53 (2010) 30353044. doi:10.1016/j.ijheatmasstransfer.2010.03.024.

[30] Y. Lia, A. Delsante, J. Symons, Prediction of natural ventilation in buildings with large openings, Building and Environment 35 (2000) 191206.

[31] R. Taylor, R. Krishna, Multicomponent mass transfer, John Wiley \& Sons, Inc, 1993.

[32] Scilab Enterprises, Scilab: Free and Open Source software for numerical computation, Scilab Enterprises, Orsay, France (2012).

URL http://www.scilab.org

[33] A. Hindmarsh, Odepack a systematized collection of ode solvers, Tech. rep., LLNL-Lawrence Livermore National Laboratory (1982).

URL https://computation.llnl.gov/casc/odepack/ 